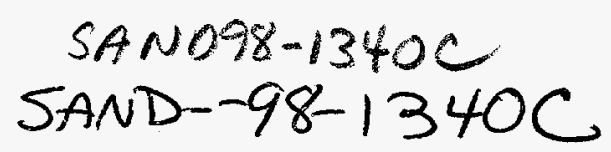

\title{
In-Vessel Tritium Retention and Removal in ITER
}

CONF-980560- -

G. Federici ${ }^{1 \dagger}$, R.A. Anderl ${ }^{2}$, P. Andrew ${ }^{3}$, J.N. Brooks ${ }^{4}$, R.A. Causey ${ }^{5}$, J.P.Coad ${ }^{3}$, D. Cowgill ${ }^{5}$, R.P. Doerner ${ }^{6}$, A.A.Haasz ${ }^{7}$, G. Janeschitz ${ }^{1}$, W. Jacob ${ }^{8}$, G.R. Longhurst ${ }^{2}$, R. Nygren ${ }^{5}$, A. Peacock ${ }^{3}$, M. Pick ${ }^{3}$, V. Philipps ${ }^{9}$, J. Roth ${ }^{8}$, C.H. Skinner ${ }^{10}$, W.R. Wampler ${ }^{5}$

1 ITER JWS Garching Co-center, Boltzmannstraße 2, 85748 Garching, Germany.

2 Idaho National Engineering and Environmental Laboratory, Idaho Falls, Idaho 83415, USA.

3 JET Joint Undertaking, Abingdon, Oxfordshire, OX14 3EA, UK.

4 Argonne National Laboratory, 9700 S. Cass Ave., Argonne, Illinois 60439, USA

5 Sandia National Laboratories, Livermore California \& Albuquerque New Mexico, USA.

6 University of California San Diego, La Jolla, California 92093-0417, USA.

7 University of Toronto, Institute for Aerospace Studies, Toronto, Ontario, Canada, M3H 5T6.

8 Max-Planck-Institut fuer Plasmaphysik, Garching, D-85748, Germany.

9 Institut fuer Plasmaphysik, Forschungzentrum Juelich, D-52425 Juelich, Germany.

10 Plasma Physics Laboratory, Princeton University, Princeton, New Jersey 08543, USA.

RECEIVES

JUN 301998

OSTI

\section{Invited Review Paper - R2}

Tritium retention inside the vacuum vessel has emerged as a potentially serious constraint in the operation of the International Thermonuclear Experimental Reactor (ITER). In this paper we review recent tokamak and laboratory data on hydrogen, deuterium and tritium retention for materials and conditions which are of direct relevance to the design of ITER. These data, together with significant advances in understanding the underlying physics, provide the basis for modelling predictions of the tritium inventory in ITER.

We present the derivation, and discuss the results, of current predictions both in terms of implantation and codeposition rates, and critically discuss their uncertainties and sensitivity to important design and operation parameters such as the plasma edge conditions, the surface temperature, the presence of mixed-materials, etc. These analyses are consistent with recent tokamak findings and show that codeposition of tritium occurs on the divertor surfaces primarily with carbon eroded from a limited area of the divertor near the strike zones. This issue remains an area of serious concern for ITER. The calculated codeposition rates for ITER are relatively high and the in-vessel tritium inventory limit could be reached, under worst assumptions, in approximately a week of continuous operation.

We discuss the implications of these estimates on the design, operation and safety of ITER and present a strategy for resolving the issues. We conclude that as long as carbon is used in ITER, the efficient control and removal of the codeposited tritium is essential. There is a critical need to develop and test in-situ cleaning techniques and procedures that are beyond the current experience of present-day tokamaks. We review some of the principal methods that are being investigated and tested, in conjunction with the R\&D work still required to extrapolate their applicability to ITER. Finally, unresolved issues are identified and recommendations are made on potential R\&D avenues for their resolution.
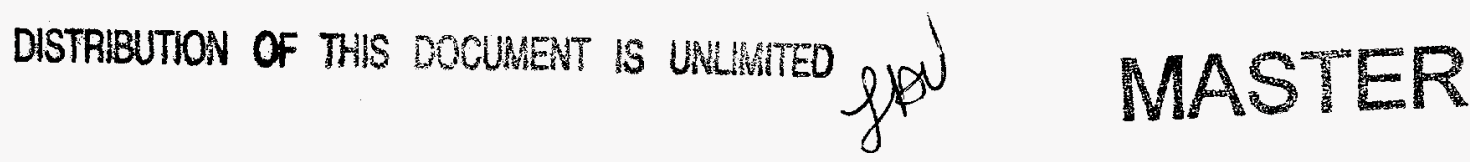

\footnotetext{
$\dagger^{\dagger}$ corresponding author: fax. +49-89-32994110; e-mail: federig@ipp.mpg.de
} 


\section{Introduction}

The International Thermonuclear Experimental Reactor (ITER) is envisioned to be the next major step in the world's fusion program from the present generation of tokamaks and is designed to study fusion plasmas with a reactor relevant range of plasma parameters.

During normal operation, it is expected that a fraction of the unburned tritium, that is used to routinely fuel the discharge, will be retained together with deuterium on the surfaces and in the bulk of the plasma facing materials (PFMs) surrounding the core and divertor plasma. The understanding of the basic retention mechanisms (physical and chemical) involved and their dependence upon plasma parameters and other relevant operation conditions is necessary for the accurate prediction of the amount of tritium retained at any given time in the ITER torus.

Accurate estimates are essential to assess the radiological hazards associated with routine operation and with potential accident scenarios which may lead to mobilisation of tritium that is not tenaciously held. Estimates are needed to establish the detritiation requirements for coolant water, to determine the plasma fuelling and tritium supply requirements, and to establish the needed frequency and the procedures for tritium recovery and clean-up.

Tritium retention as explained in Ref. [1] is expected to strongly depend upon the PFMs selected for protection of the various in-vessel components. To date, there are still large uncertainties in quantifying the in-vessel tritium inventory of ITER. They arise mainly from the plasma edge physics parameters, which are anticipated to strongly affect the erosion, deposition and codeposition patterns and rates. Moreover, the simultaneous use of beryllium to protect the main portion of the first-wall, and tungsten and carbon-fibre-composites (CFCs) to protect the divertor, introduces significant uncertainties for the operation of a tokamak like ITER. The anticipated formation of complex mixed-material layers whose behaviour in terms of erosion, tritium retention and removal remains highly uncertain, complicates the interpretation.

An understanding of the relative importance of the retention mechanisms as well as quantitative estimates of the inventory comes both from experiments in existing tokamaks and from laboratory experiments designed to probe fundamental processes. These experimental results are being used to validate models of tritium retention in ITER. The ongoing effort on the validation of codes required to interpret tokamak data and to build confidence in predictions for ITER is addressed in two papers at this conference $[2,3]$. Tritium issues in 


\section{DISCLAIMER}

This report was prepared as an account of work sponsored by an agency of the United States Government. Neither the United States Government nor any agency thereof, nor any of their employees, makes any warranty, express or implied, or assumes any legal liability or responsibility for the accuracy, completeness, or usefulness of any information, apparatus, product, or process disclosed, or represents that its use would not infringe privately owned rights. Reference herein to any specific commercial product, process, or service by trade name, trademark, manufacturer, or otherwise does not necessarily constitute or imply its endorsement, recommendation, or favoring by the United States Government or any agency thereof. The views and opinions of authors expressed herein do not necessarily state or reflect those of the United States Government or any agency thereof. 


\section{DISCLAIMER}

Portions of this document may be illegible electronic image products. Images are produced from the best available original document. 
tokamaks were the subject of a recent IEA workshop and a summary of this workshop is being prepared for Nuclear Fusion [4].

As part of the R\&D program supporting the engineering design activities (EDA) of ITER, new relevant data are becoming available from various laboratories, particularly for $\mathrm{Be}$ and for $\mathrm{W}$, where previously data were either missing or largely scattered. Based on these data and on the advances in the related modelling, it is now possible to conclude that for ITER, the dominant mechanism for hydrogenic retention is codeposition of carbon and possibly beryllium (the latter predominantly when abundant $O$ is present). Retention by other mechanisms such as implantation and surface absorption, which may be significant for small short-pulse machines, is expected to rapidly reach saturation in ITER. The implantationdriven inventory in these components by the end of the Basic Performance Phase (BPP) may be only a few tens of grams, and most of that will be produced by neutron transmutations in the Be itself.

The tritium residing in the $\mathrm{C}$-codeposited layers may be mobilised under accident conditions and its accumulation in the torus must be controlled. At a certain level set by licensing considerations, plasma operation must be discontinued and dedicated cleaning techniques/ procedures must be applied until the tritium inventory is significantly reduced. Therefore, a need exists to develop and test in-situ cleaning techniques that are beyond the current experience of tokamaks. As long as carbon is used in ITER, efficient methods to control and remove the codeposited tritium will be required.

The organisation of this paper is as follows. Section 2 provides an overview of the design and operating conditions of the main components which define the plasma boundary of ITER. Section 3 reviews the erosion database and the results of recent relevant experiments conducted both in laboratory facilities and in tokamaks. These data provide the experimental basis and serve as an important benchmark for both model development (discussed in Sec. 4) and calculations (discussed in Sec. 5) that are required to predict tritium inventory build-up in ITER. Section 6 emphasises the need to develop and test methods to remove the tritium from the codeposited C-based films and reviews the status and the prospects of the most attractive techniques. Sec. 7 identifies the unresolved issues and provides some recommendations on potential R\&D avenues for their resolution. Finally, a summary is provided in Sect. 8 .

\section{ITER PFC design and operation overview}


A detailed description of the design features and operational aspects of the ITER plasma facing components (PFCs) is given in Ref. [5] and references therein. Here, we limit our attention to some specific aspects of the design and operation of the plasma-facing and plasma-limiting components which are expected to affect erosion/ redeposition, tritium retention and removal.

\subsection{In-Vessel Components: configuration and materials}

A cross-sectional view of ITER, showing the various PFCs, is portrayed in Fig. 1. The divertor PFCs are mounted on individual removable cassettes for flexibility of choice and for rapid maintenance, and can be replaced in the hot cell by special semi-automatic tools. They include $>1 \mathrm{~m}$ long vertical targets outboard of the separatrix with water-cooled $>100 \mathrm{~mm}$ thick stainless steel bodies, water-cooled copper heat sinks clad with $\mathrm{W}$ in the upper part and with CFC in the lower part, target/liner assemblies clad with CFC on a small area of the dump target and with $\mathrm{W}$ of broadly similar construction to the vertical targets, on the majority of the surface, as well as a W clad water-cooled copper dome.

Although the utilisation of CFC is known to exacerbate the problem of tritium codeposition and mixing of materials, its use at the divertor target, near the strike points, is presently viewed as indispensable to withstand, with a reasonable erosion lifetime, the high thermal loads expected during attached-plasma transients and disruptions.

On the rest of the plasma facing walls, various types of shielding modules can be distinguished by the functional requirements of their first-wall.

- The primary modules have a first-wall designed to accommodate $0.5 \mathrm{MW} / \mathrm{m}^{2}$, and are in direct contact with the plasma only during off-normal events. Beryllium (S65C) is used here as the PFM, because of its plasma-compatible low atomic number, its good oxygen gettering properties, and its ability to protect the underlying first-wall structures from the off-normal thermal loads. It also offers the prospect of repair by plasma spray. The specified Be thickness is $10 \mathrm{~mm}$.

- The baffles are the portion of the first-wall adjacent to the divertor. Their function is to retain the recycling neutrals inside the divertor. The baffle modules are not normally in contact with the plasma, but are subject to moderate heat loads caused by MARFEs and the charge exchange flux arising from neutral-plasma interactions near the entrance to the divertor channel. They are designed to accommodate heat loads up to $3 \mathrm{MW} / \mathrm{m}^{2}$. 
Beryllium protects the upper regions of the baffle, while $W$ is used in the lower baffle near the divertor to minimise the sputtering erosion from charge-exchange neutrals due to its higher sputtering threshold energy compared to that of $\mathrm{C}$ or $\mathrm{Be}$.

- The port limiters are located in two of the equatorial ports for improved maintainability. They see a much higher heat flux than the blanket modules, up to $\sim 10 \mathrm{MW} / \mathrm{m}^{2}$ during start-up and shutdown ( 50 seconds each), and are designed to provide an acceptable critical heat flux $(\mathrm{CHF})$ margin during limiter operation. The specified Be thickness is 4$5 \mathrm{~mm}$.

\section{Include here Figure 1}

\subsection{Operational scenario and conditions}

ITER operation is presently envisaged in two phases: the Basic Performance Phase (BPP) and the Enhanced Performance Phase (EPP), each planned to last about 10 years. The set of nominal design parameters and BPP operation conditions adopted for the analysis is discussed in Sect. 5. Plasma operation will be preceded by a year of integrated commissioning of the sub-systems, followed by a few years of initial operation in hydrogen to gain operating experience in a non-radioactive environment, followed by a brief D-D phase before proceeding to operation with D-T. Various operational modes are envisaged, including ohmic and additionally heated pulses, $1000 \mathrm{~s}$ ignited pulses, and longer pulses assisted by current drive.

Erosion/ redeposition is one of the crucial physical issues to be faced in the design of plasma facing components for ITER. The erosion of PFMs produces impurity influxes which degrade plasma performance and redistribute the wall material due to poloidally asymmetric transport. Results are now available from several divertor tokamaks, indicating that the first-wall is an area that experiences net erosion while the divertor has areas of erosion (outer leg) and heavy deposition (inner leg). Dust is also an important consequence of erosion. It represents a potential safety hazard for ITER because it can cause steam-induced hydrogen explosions, and it can increase the spread of radioactivity during an accident involving a sudden vent, if mobilised. The study of dust production and the formation and erosion of mixed materials has just begun (see for example Ref. [6] and Sect. 7.5).

The amount of material eroded from the PFMs by sputtering, chemical reactions, ablation and melt-layer loss will be much greater (at least by a factor $10^{3}$ ) for ITER compared to presentday tokamaks because of the longer pulse length and cumulative run-time, together with the 
high heat loads and densities and more intense disruptions. For the most severe design assumptions, the erosion lifetime of the divertor PFCs will be sufficiently short, requiring about three replacements during the BPP. In present experiments, by contrast, the net erosion is barely measurable. Thus, for the first time in fusion research, erosion and its consequences (e.g., codeposition) will determine the operational schedule of a fusion device. As laboratory measurements have shown that these codeposited films when exposed to air completely decompose releasing tritium at a temperature $250 \mathrm{C}$, they are considered a risk under ITER accident conditions, and their accumulation will be strictly controlled on safety grounds. Based on the release from postulated accident sequences, $1000 \mathrm{~g}-\mathrm{T}$ is the presently assumed in-vessel tritium mobilisable limit. When the accumulated torus inventory reaches this level, operation must be discontinued and dedicated cleaning techniques/ procedures applied until the tritium inventory is reduced significantly. The frequency of cleaning intervention will be simply determined by the rate of codeposition. Independent of safety limits, control of the invessel tritium inventory is also necessary to avoid exhausting the available tritium supply. However, it is assumed here that the most stringent requirements will come from the safety considerations.

\section{Tritium retention database with direct relevance to the design of ITER}

One of the main concerns with plasma-facing materials is erosion due to plasma particle impact. In the case of $\mathrm{Be}$ and $\mathrm{W}$, physical sputtering is expected to be the controlling erosion mechanism, while for carbon, under certain plasma conditions, radiation-enhanced sublimation (RES) and, in particular chemical erosion, will dominate [7, 8, 9]. Here, we provide a synopsis of the database of the chemical erosion of carbon for which some unresolved critical issues still remain. Resolution of these issues is urgently needed as the outcome could affect ITER component lifetime and codeposition predictions.

\subsection{Chemical erosion}

At present, the mechanisms associated with chemical erosion of carbon due to hydrogen impact are not fully understood. Recent modelling advances $[10,11,12,13]$, however, have provided new insights into the complex physical/chemical interactions. Work on this front is continuing.

While the chemical erosion database generated by controlled laboratory experiments is extensive for incident $\mathrm{H}$ energies above $\sim 50 \mathrm{eV}$ [7], it is only recently that the range has been extended down to divertor-relevant energies, $\sim 10 \mathrm{eV}[14,15]$. A major limitation of controlled 
ion beam experiments is the available fluxes at low energies from mass-analysed accelerators or ion guns. Alternatively, laboratory plasma devices capable of delivering high fluxes are constrained by other difficulties, such as reliable plasma characterisation and the effect of redeposition of eroded carbon on the derived erosion yields. The complexity of fusion devices makes it even more difficult to measure erosion yields in tokamaks. Indirect methods are used to determine the flux densities and energies of the impacting and eroded particles. The most advanced method is emission spectroscopy in the plasma edge as discussed in [9].

In brief, the current chemical erosion database at divertor-relevant fluxes is insufficient to draw conclusions, with confidence, on the possible nature of the flux dependence of the chemical erosion yield of carbon. The scatter in the available data, spanning the flux range $10^{18}-10^{23}$ ions $/ \mathrm{m}^{2} \mathrm{~s}$, is too large to discern a significant flux dependence $[8,9]$. Recent studies, dedicated to investigating the flux range between $10^{21}$ and $10^{23}$ ions $/ \mathrm{m}^{2} \mathrm{~s}$, show the possibility of a reduced yield with increasing flux $[16,17]$. However, due to the potential importance of a flux dependence effect for ITER, it is necessary to expand the available experimental database at high fluxes $\left[>3 \times 10^{22} \mathrm{D} / \mathrm{m}^{2}\right.$ s]. Plasma devices such as PSI-1 (at IPP, Berlin) and PISCES (UCSD) are capable of delivering the high fluxes, but the quantification of the reaction products in mass spectrometry or optical emission spectroscopy is complicated by the varying plasma conditions resulting from flux variation. For erosion measurements it is recommended that, in conjunction with experimental plasma controls and diagnostics, plasma modelling be undertaken for experiments to be performed in plasma simulator devices. A comprehensive mapping of the plasma, coupled with particle transport and redeposition calculations, will give net erosion predictions which, when compared with mass loss measurements, could be used to derive erosion yields.

Notwithstanding the above limitations, a careful assessment of the available low-energy chemical erosion database was undertaken in an attempt to provide divertor relevant yields for erosion/codeposition calculations being performed by Brooks [2] for ITER. As most of the controlled laboratory yield data were obtained at fluxes $<10^{20} \mathrm{ions} / \mathrm{m}^{2} \mathrm{~s}$, a key requirement is to project the low-flux results to divertor fluxes. In addition, the incident $D$ energy needs to be extrapolated to $\sim 5 \mathrm{eV}$, which is below the lowest energy $(10 \mathrm{eV})$ for which measured yields are available. Also, $\mathrm{H}$ and $\mathrm{D}$ data need to be projected to tritium. Table 1 comprises the 'mean values' of projections arrived at by two different procedures. For the most part, the tabled values are within a factor of two of the two sets of projections. The two procedures are briefly described: (i) The 'Garching' procedure is based on an erosion model [12], which 
includes terms for energy and mass dependence through a sputtering-like function added to the thermal model of Horn et al. [10]. A flux-dependence correction term was also added to get agreement with experimentally measured yields. (ii) The second approach, the 'Toronto' procedure, is based on a set of chemical erosion measurements at low energies (down to $10 \mathrm{eV})[15]$ and an erosion model [15], incorporating kinetic and thermal processes in a selfconsistent way. Thus, projections down to $5 \mathrm{eV}$ and to tritium were obtained using the model. Projections to high fluxes $\left(\sim 10^{23}\right.$ ions $\left./ \mathrm{m}^{2} \mathrm{~s}\right)$ were made on the basis of an experimentally observed trend that $T_{m}$ (temperature where maximum chemical erosion is observed) shifts to larger values with increasing flux density $[18,19]$.

\section{Include here Table 1}

Other chemical erosion issues relevant for ITER include the effect of dopants (e.g., $\mathrm{Si}$ ) on the erosion yield of doped graphite, and the erosion behaviour of redeposited carbon surfaces. Based on the extensive experimental database on the chemical erosion of doped graphites [e.g., 20, 21], yield reductions are observed for relatively high (>100 eV) impact energies and temperatures $>430^{\circ} \mathrm{C}$, i.e. at the maximum of the chemical sputtering yield. At energies < $100 \mathrm{eV}$ and temperatures $<430^{\circ} \mathrm{C}$, the yield reductions are minor and are comparable to the reduction observed in the $\mathrm{C}$ concentration at the surface [20].

In view of the fact that the projected high 'gross chemical erosion yield' for the ITER divertor is balanced by local redeposition [2], the question of stability and enhanced erosion of the promptly redeposited material arises. Due to the lack of experimental data at low impact energies characteristic of the divertor, we resort to the findings of Vietzke et al. [7] for thermal atomic $\mathrm{H}$ impact on various forms of hydrogenated materials. They observed significantly enhanced rates for the hydrogenated materials in comparison to pyrolytic graphite. This is in agreement with erosion experiments using low-pressure plasmas showing that, in particular at low ion energies (10 to $20 \mathrm{eV}$ ), the erosion rates depend critically on the microscopic film structure [22].

\subsection{Tritium codeposition experience}

\subsubsection{Tokamaks}

$D$ retention has been measured in many tokamaks including studies of trace tritium produced by $\mathrm{D}-\mathrm{D}$ nuclear reactions. However, the most extensive data on $\mathrm{D}$ and $\mathrm{T}$ codeposition has come from TFTR and JET. Here we concentrate on the experience of these tokamaks in this section. 
The Tokamak Fusion Test Reactor (TFTR) was the first fusion facility with extensive experience with tritium fuelling and removal. A total of $100 \mathrm{~g}$ of tritium was processed by TFTR with $5 \mathrm{~g}$ of tritium fuel supplied to the plasma by neutral beam injection and gas puffs. The tritium fuelling and retention history is shown in Table 2. The fraction of tritium retained in the vessel was found to vary with discharge type, clean-up history and the period studied ([23] and references therein). The modelling of tritium retention in TFTR is reported in Ref. [3]. Overall, during the three periods of DT plasma operations (excluding periods of active tritium removal), over half of the tritium fuel injected was retained in the torus. Active tritium removal by glow discharge cleaning (GDC) and air ventilation and other techniques (see section 6.2.1) was successful in removing substantial amounts of tritium in periods between plasma operations. The current in-vessel inventory is less than $1 \mathrm{~g}$. The tritium fraction retained was similar to the deuterium retention fraction estimated earlier from in-vessel surveys and analysis of components, including wall coupons and a standard set of limiter tiles removed after each major run campaign [24] as well as from the fuel balance analysis [25]. The $\mathrm{D}$ retention fraction compared to the injected amount averaged over the 5 year period was $44 \pm 17$. The $\mathrm{D}$ inventory was estimated from in-vessel surveys and analysis of components removed after each major run campaign. This value agreed with the retention fraction of $35 \pm$ $22 \%$ from fuel balance studies for high power neutral beam heated plasmas [26]. These studies showed that the dominant mechanism for deuterium retention was codeposition of carbon with deuterium. $44 \%$ of the retained $\mathrm{D}$ was on the plasma-facing surface of the limiter, $15 \%$ was in the gaps between the limiter tiles and $41 \%$ was on the remainder of the stainless steel vacuum vessel wall.

An extended phase of D-T operations was also carried out in the Joint European Torus (JET) from June to November 1997 as part of the Mk II divertor campaign [27, 28]. During the D-T phase of 1997 (referred to as DTE1), $35 \mathrm{~g}$ of tritium entered the torus, of which $34.4 \mathrm{~g}$ was as gas fuelling and $0.6 \mathrm{~g}$ as neutral beams $[27,28]$. The $T$ was introduced in a mixture with $D$, with the $\mathrm{T}$ content varying from $1 \%$ to $100 \%$. Immediately after the last $\mathrm{T}$-fuelled discharge, the amount of $\mathrm{T}$ remaining in the vessel was $\sim 12 \mathrm{~g}$. A series of discharges was performed with $\mathrm{D}$ or $\mathrm{H}$ fuelling, resulting in a reduction of the fraction of tritium in the plasma similar to that following the JET Preliminary Tritium Experiment (PTE1) in 1991 [29], before the pumped divertor was installed. However, the $\mathrm{T}$ remaining in the vessel was only reduced by about one-half, to $\sim 6 \mathrm{~g}$, whereas after PTE1 it was reduced by $87 \%$ (see Table 2). 
During the Mk II campaign, but prior to the DTE1 experiment, heavy deposits were discovered on water-cooled copper louvres through the gap at the inner corner of the divertor (see Fig. 2). These deposits were tending to flake off, probably on exposure to air. They represent an extra, and larger, contribution to the retained D inventory than in previous JET operational campaigns [30]. Therefore, it is presently assumed that much of the tritium remaining in the vessel after DTE1 is trapped in such deposits. Since the regions of the deposits cannot be contacted by the plasma, they are unaffected by plasma discharge clean-up operations. However, anomalously high $\mathrm{T}$ outgassing rates were found upon venting in comparison to that after PTE1. Efforts are underway to model the deposition patterns resulting from a selection of typical JET discharges, to see if the main features of the $D$ retention in JET (including the location of the $\mathrm{C}$ source and the plasma conditions that have produced the films) can be reproduced, together with the absolute quantities. These features include far greater deposition at the inner than the outer divertor legs, and the heavy deposition at the cold surfaces through the gap at the inner divertor corner. Satisfactory agreement would be necessary before extrapolation to ITER could be made with confidence. Further important information is expected to be gained from future operation of JET with the so-called divertor gas-box configuration. A poloidal set of divertor tiles, together with a selection of inner wall and outer poloidal limiter tiles, have been removed for detailed analysis of $\mathrm{D}$ and $\mathrm{T}$ content, distribution and profile. Samples of tokamak dust and flakes from the heavy deposition at the inner corner of the divertor have also been retrieved for detailed analysis for composition, size, $\mathrm{T}$ and $\mathrm{D}$ content, specific surface area, etc.

\section{Include table 2}

\section{Include figure 2}

\subsubsection{Laboratory studies}

In addition to the information available from tokamaks, the codeposition of hydrogenic species with ITER candidate plasma facing materials is also being extensively studied in laboratory experiments, where individual processes can be investigated and understood in isolation and where conditions are better controlled and diagnosed than in tokamaks.

While there is a very large database and many publications on the subject of codeposition of carbon with tritium (see for example work mentioned in Ref. [1] and Ref. [22]), the data on the codeposition properties of beryllium are much more limited. New results on the 
codeposition or co-implantation of beryllium and deuterium are now available from Causey et al. [31], and Mayer et al. [32,33]. The results of these investigations indicate that hydrogen isotope retention in re-depositing $\mathrm{Be}$ is very dependent on the relative magnitudes of the hydrogen and beryllium fluxes and the fluxes of oxygen and carbon that are incident on the collecting surface, as well as on the energy of the incident hydrogen. If the oxygen and carbon impurity fluxes are comparable to the hydrogen and beryllium fluxes, the re-depositing $\mathrm{Be}$ layer will most likely grow as a $\mathrm{BeO}$ layer with incorporated carbon. If the hydrogen is energetic enough to be implanted in the $\mathrm{BeO}$ layer and causes displacement damage, it will be retained at the damage sites. Retention will saturate at $\mathrm{D} / \mathrm{Be}$ of about 0.35 . If the oxygen and carbon impurity fluxes are significantly less than the hydrogen and beryllium fluxes, the redepositing layer will probably be relatively pure Be with low oxygen and carbon impurities. Hydrogen retention will be low and dependent on the formation of near surface bubbles and blisters. Temperatures above $500 \mathrm{C}$ are needed to remove retained hydrogen from codeposited $\mathrm{BeO} / \mathrm{C}$ layers formed with energetic (hundreds of $\mathrm{eV}$ ) hydrogen. Retention of hydrogen in redeposited Be with low oxygen and carbon impurities approaches zero for temperatures above $300 \mathrm{C}$.

In conclusion, the estimation of tritium retention in re-deposited Be for ITER is highly dependent on our knowledge of the oxygen and impurity fluxes incident on the collecting surfaces and this is accounted for in the calculations. At the temperatures proposed for air or oxygen baking of the codeposited carbon layer (see Sec. 6), the codeposited beryllium layer is effectively depleted with no oxygen addition. The effect of oxygen on the release of hydrogen from mixed-Be/C layers needs to be investigated.

\subsection{Implantation experience}

New important implantation data are now available for beryllium and for tungsten alloys, for conditions representative of ITER where previous data were either missing or largely scattered. The majority of studies conducted to date have sought to understand the processes of implantation-driven diffusion, trapping and release at the surface.

Beryllium: retention data for beryllium have been, at least in part, presented previously [1]. A review has been recently compiled by Anderl et al. [34]. A key finding observed in high ionflux experiments is the saturation of the beryllium surface such that inventories of implanted particles become almost insensitive to continued implantation fluence. This phenomenon has 
a strong impact on the design of ITER because it implies a small inventory in the beryllium components as discussed Sec. 5. D(T) retention in beryllium was found to vary strongly with temperature and is reduced by about one order of magnitude as the temperature varies from $27 \mathrm{C}$ to $700 \mathrm{C}$. The maximum $\mathrm{D}(\mathrm{T})$ retention is about $1 \times 10^{21} \mathrm{D}(\mathrm{T}) / \mathrm{m}^{2}$ or less for ITER-relevant plasma-exposure conditions. Measurements of the retained $\mathrm{D}$ using nuclear reaction analysis (NRA) are comparable to those based on thermal desorption (TDS) for $200^{\circ} \mathrm{C}$ surface temperature and plasma exposure in the steady-state-reflex-arc plasma generator PISCES-B at the University of California San Diego [34], but the NRA results are lower than TDS data for $500^{\circ} \mathrm{C}$ plasma exposure. This indicates that a low $\mathrm{D}$ concentration could extend deeper into the bulk with a concentration below the 10-appm detection sensitivity of the NRA. Finally, for comparable test conditions, plasma-exposure in PISCES-B results in less D retention in plasma-sprayed $\mathrm{Be}$ than in fully dense $\mathrm{Be}$.

Studies have also been initiated to investigate hydrogen isotope retention in beryllium whose surface is contaminated with carbon and oxygen. This condition may result in ITER because of the erosion-redeposition phenomena that are anticipated to generate complex mixedmaterial layers whose behaviour in terms of tritium retention and removal are is not well known. While mixed-material layers are expected to play a major role only in the ITER divertor, during disruptions there might be transiently an outflux of $\mathrm{C}$ from the divertor that could lead to deposition onto the surfaces of the first-wall. The results of preliminary investigations conducted to date are discussed in ref. [34]. Most of the effort is dedicated to the investigation of conditions necessary for the formation of mixed-material layers involving carbon, beryllium and tungsten [35]. The available results, although preliminary, indicate that below $\sim 0.2 \% \mathrm{C}$-impurity fraction, Be samples exposed at any temperature remained free of Cmixed material layers. As the concentration in the plasma is increased, e.g. in the experiment [35] by $C D_{x}$ injection, surface layers are observed to form at elevated temperatures (i.e., 500C). Once the C-impurity fraction reaches $\sim 3 \%$, mixed-material layers are observed to form even at room temperature (RT). It is observed that if C-containing mixed-material layers form, the total deuterium retention tends to increase, but is not significantly greater than the $D$ uptake and retention in $\mathrm{Be}$ without an impurity layer [35]. For temperatures above $400^{\circ} \mathrm{C}, \mathrm{Be}$ diffuses into carbon overlayers, and at temperatures between $500^{\circ} \mathrm{C}$ and $600^{\circ} \mathrm{C} \mathrm{Be}_{2} \mathrm{C}$ is formed. Hydrogen retention is found to be very low in $\mathrm{Be}_{2} \mathrm{C}$ at these temperatures [36]. 
The effect of beryllium deposition onto a carbon sample also needs to be examined. Beryllium incident in the bombarding plasma may act to reduce the chemical erosion of a graphite plate, in much the same manner as the addition of dopants to graphite have been shown to reduce chemical erosion. This could potentially have a big impact on the erosion of the graphite divertor plates in ITER.

Tungsten: ITER-relevant experiments on hydrogen isotope retention in various forms of tungsten (with energies below the displacement threshold for hydrogen isotopes in tungsten) have been performed at several laboratories during the last few years $([37,38,39])$. Additionally, Franzen et al. [40] provided an excellent summary of previous work. Preliminary modelling of the retention data shows that hydrogen release from tungsten is not recombination limited. In addition, it appears that intense implantation such as that expected in the divertor region of ITER (and duplicated in plasma simulators such as PISCES-B and the Tritium Plasma Experiment (TPE) located at LANL) results in enhanced reemission from the implant zone. This phenomenon results in very low hydrogen retention. Tungsten samples containing $1 \%$ lanthanum oxide examined several days after exposure to intense plasmas in the TPE (flux $=8.7 \times 10^{21} \mathrm{~T} / \mathrm{m}^{2}-\mathrm{s}, \mathrm{E}=100 \mathrm{eV}$ ), retained only a very small fraction $\left(<2 \times 10^{-5}\right)$ of the implanted tritium. For example, the sample exposed to the above flux for 4 hours at $450 \mathrm{C}$, retained less than $10^{21} \mathrm{~T} / \mathrm{m}^{2}$.

Based on these data, while the modelling has shown the release of hydrogen from tungsten to be rapid, there is still a build-up of trapped atoms at moderate temperatures (130 to 530C). NRA profiling of these deuterium plasma exposed samples [38] shows the near surface deuterium concentration at a level of about 0.1 atomic percent. Similarly, NRA measurements on a $25 \mu \mathrm{m}$ thick $\mathrm{W}$ foil implanted with $500 \mathrm{eV} \mathrm{D} \mathrm{D}^{+}$at $230 \mathrm{C}$ [39] also gave concentrations of $\sim 0.1$ at $\%$, on both front and back surfaces. Based on TDS measurements, however, there was no indication that the foil was saturated [39]. Saturation of a $10 \mathrm{~mm}$ thick tungsten layer to this level with a 50/50 mixture of deuterium and tritium would result in less than $0.5 \mathrm{~g}-\mathrm{T} / \mathrm{m}^{2}$. As temperatures in the divertor of ITER are expected to exceed, at least periodically, 150 to $530 \mathrm{C}$, the trapped tritium is not expected to remain at even this level. NRA measurements do indicate that D trapping occurs in the bulk of tungsten [39], thus the contribution to trapping at damage sites created by neutrons will also need to be considered. Due to the residual radiation in tungsten after exposure to neutrons, it is not expected that experiments will be available on the tritium retention in neutron irradiated tungsten 
Scanning electron microscopy (SEM) has been performed for the samples exposed in the PISCES-B facility. Microscopic pits of sizes ranging from $0.1 \mu \mathrm{m}$ to $5 \mu \mathrm{m}$ were observed in $1 \%$ lanthanum oxide doped $\mathrm{W}$ samples exposed to extended deuterium plasma bombardment. These pits may result from the formation, and subsequent rupturing, of deuterium bubbles formed at defect sites and grain boundaries below the sample surface. The erosion rate associated with this phenomenon, although enhanced, is still small $\left(10^{-4}\right)$ at ITER wall temperature. The damaged surface structure appears to be beneficial by allowing enhanced reemission of deuterium from the sample.

Measurements are also underway to investigate C-containing layers formation on tungsten [41]. When exposed to a plasma containing $1 \% \mathrm{C}$, it was observed that tungsten develops a mixed-material coating during high-temperature exposure $\left(750^{\circ} \mathrm{C}\right)$ and remains clean during room-temperature exposures $\left(50^{\circ} \mathrm{C}\right)$. Similarly, by lowering the $C$ concentrations $(0.2 \%)$ in the plasma, tungsten surfaces can remain uncoated during high-temperature exposure. D retention in the tungsten samples which remain uncoated during exposure, is an order of magnitude higher in the retention for room temperature exposures compared to $750^{\circ} \mathrm{C}$ exposures. When a carbon-containing mixed-material layer forms, the retention increases, primarily due to the high retention capacity in the carbon film. Experimental details can be found in Ref. [41].

\section{Modelling of D-T retention}

We describe here the results of several different modelling efforts aimed at providing understanding of the mechanisms expected to govern the tritium uptake in ITER. Emphasis of modelling is on implantation in beryllium and tungsten and codeposition in carbon and beryllium.

\subsection{Modelling of Implantation in Beryllium and Tungsten}

Codes that model hydrogen transport and retention in materials such as beryllium include DIFFUSE [42], PIDAT [43], and TMAP4 [44].

One process not built into most of the models is saturation. This became evident in experiments with high particle fluences and high fluxes, particularly for beryllium, but also more recently for tungsten at ambient temperatures. After reaching fluences of about $10^{22}$ atom $/ \mathrm{m}^{2}$, it has been observed that further implantation results in a negligibly increased inventory $[45,46,47]$. Details of mechanisms responsible for this effect are only partially 
understood [48], but two factors seem to be important-low capacity for hydrogen in the material and a high implantation flux which generate surface-connected porosity that provides a rapid return path back to the plasma. Evidence of such damage has been reported by several authors $[46,47,49,50]$. This inhibits the driving potential for diffusion deeper into the layer, restricting the total inventory.

Figure 3 compares tritium build-up calculated for the ITER Be first-wall in the BPP using recombination-limited re-emission and saturation effects applying the TMAP4 code.

\section{Include Figure 3}

For very long exposure times, such as may be encountered in ITER, the thinning of the plasma-facing material by erosion must also be considered since it will hasten tritium breakthrough and reduce tritium inventories.

A further consideration, at least for beryllium in tokamak applications, is the production of helium and tritium by neutronic transmutations in the beryllium itself. These processes are incorporated into the FISPACT code [51,52] which was used by Forty et al. [53] to estimate gas and other reaction product generation rates in a typical tokamak configuration. Based on results of measurements of tritium release from $\mathrm{n}$-irradiated beryllium conducted by Baldwin and Billone [54], it is assumed that this tritium is not released at the temperature reached during normal operation and accident conditions in ITER and is distributed throughout the bulk material, retained primarily in microscopic defect sites and voids containing helium

A measure of the predictive capability of any model is its ability to give reasonable replications of a variety of experimental data. The TMAP4 code has been used with saturation and erosion effects to successfully model a number of experiments $[47,49,55,56]$ as discussed in Ref. [48]. The model gave good results in each of the cases mentioned.

The TMAP4 code has also been used to simulate experiments performed on pure tungsten and on tungsten doped with about $1 \%$ of $\mathrm{La}_{2} \mathrm{O}_{3}$ that were exposed to deuterium and tritium plasmas [38] and to ion beam implantation-driven permeation experiments [57]. Similar results were seen for tungsten samples that had been exposed to ion beams by Haasz and Davis [46]. In each case, there was a break point in temperature above which classical recombination-limited re-emission of implanted ions from the surface seemed to apply using literature values for trapping and transport parameters [57] and below which classical 
concepts proved inadequate to model the measured retention. The temperature at which that break point occurred was higher for higher ion flux densities. Analyses [58] showed that these retention profiles, together with deuterium concentration profiles measured by NRA [59], could be reproduced by simply enhancing transport of implanted atoms from the implantation depth back to the surface, a process that appears to be characteristic of saturation. Further work remains to establish the mechanism(s) for this enhanced transport.

\subsection{Erosion/codeposition modelling}

The purpose of this work is to assess the wall and divertor component lifetimes due to sputtering, the tritium codeposition rates in redeposited material, and the likely effect on core plasma contamination. A combination of kinetic impurity transport codes, sheath code, and charge-exchange code was used, all coupled to plasma fluid type solutions for the divertor scrape-off layer [60]. Briefly, the central technique is to use a combination of the WBC [61] Monte Carlo code and the REDEP [62] deterministic code. Both codes use single-particle kinetic treatment given a fixed plasma background. WBC is a sub-gyro orbit code with, in principle, all relevant processes includable. It is, however, time consuming. REDEP uses gyro-orbit averaging and other numerical time saving techniques and is in the order of 100 times faster. To compute divertor or first-wall erosion, these codes are coupled, with WBC supplying very detailed space-localised impurity parameters (e.g. redeposited charge state distribution) to REDEP which is then used to generate a self-consistent solution (erosion, redeposition, self-sputtering fluxes, etc.) for the entire surface.

Both codes incorporate numerous models and sub-codes for sputtering and reflection coefficients, atomic and molecular processes, plasma-impurity collisions, surface temperature and temperature-dependent hydrogen isotope trapping ratios, and sheath parameters. Critical models for the plasma regime and design analysed here include carbon chemical sputtering coefficients at low energies $(\sim 5-15 \mathrm{eV})$, rate coefficients for hydrocarbon molecular impact processes with plasma ions and electrons, hydrocarbon sticking coefficients, and the effects of mixed materials, namely beryllium and carbon, on sputtering and tritium trapping. Some details of these critical models are given in Ref. [2].

Clearly, the reliability of the code output for erosion/codeposition can be no better than the input plasma solution. For this work the plasma parameters are taken from the B2 EIRENE 
code solutions of Kukushkin et al. [63] with low-variance charge exchange fluxes additionally supplied by a DEGAS ${ }^{+}$code solution $[2,64]$.

In a recent code validation effort on DIII-D [65] using probe and other measured near-surface plasma data as input to the WBC and REDEP erosion codes, the code predictions were found to match erosion data well, for the overall carbon divertor and for several metal test spots. This was done for an attached plasma regime $\left(\mathrm{T}_{\mathrm{e}} \sim 70 \mathrm{eV}\right)$. This provides some confidence that given a plasma solution, the erosion/codeposition estimates would be reasonably valid for the attached portion of the divertor targets, as well as the first-wall. Currently, most tritium codeposition for the ITER reference design is predicted to arise from chemical sputtering and subsequent transport in the detached portion of the plasma along the divertor plates. As calculations for this regime are not yet validated, and in any event involve numerous model uncertainties, one needs to await considerable additional data and validation work to claim to have a predictive solution. However, the results shown here should be nevertheless reasonably valid to illustrate trends. Code validation work with carbon surfaces exposed to detached plasmas has begun for several devices, namely DIII-D, JET, and PISCES. In general, however, this effort is substantially too small in comparison to the experimental data available and to the different machines and geometries used.

\section{Analysis and estimates of tritium inventory}

\subsection{Implantation analysis (including breeding for beryllium)}

The retention and permeation of tritium in beryllium- and tungsten clad plasma-facing components of ITER have been studied using the TMAP4 code [44] including saturation and erosion adopting the set of nominal design parameters and operation conditions summarised in Table 3. By far the largest contributor of tritium in the first-wall will be tritium bred from neutron transmutations in the beryllium. Table 4 shows the estimated inventory and integrated permeation through the various PFCs.

\section{Insert Table 3}

Insert Table 4

\subsection{Erosion/codeposition analysis}

Using the WBC/REDEP/DEGAS ${ }^{+}$analysis described above and in [2], sputtering erosion/ and redeposition of the inner and outer carbon coated ITER divertor target plates were 
analysed. The analysis computes physical sputtering by plasma D-T ions and atoms, helium, carbon self-sputtering, and chemical sputtering by $\mathrm{D}-\mathrm{T}$ ions, atoms, and non-thermal molecules. Chemical yields used for the critical detached plasma region are given in Table 1 . Transport and redeposition of carbon back to the plates themselves, and to the plenum region is computed. Tritium codeposition in net carbon growth areas is computed using the redeposited carbon fluxes, and surface-temperature-dependent $\mathrm{H} / \mathrm{C}$ trapping ratios.

Ref. [2] describes some detailed results of these calculations. Regarding tritium codeposition, the critical results are: (1) carbon chemical sputtering in the detached region along each plate is the main source of net carbon erosion and tritium codeposition, (2) physical sputtering of the entire plate contributes about $20 \%$ to the codeposition, (3) chemical sputtering in the attached regions has essentially no contribution to net erosion (due to $\sim 100 \%$ redeposition), (4) $\sim 75 \%$ of growth/codeposition occurs on the bottom of the divertor and/or dump plates, and $\sim 25 \%$ occurs in the private-flux region.

Various parameter sensitivity studies were performed for the codeposition calculations, as discussed further in [2]. Most studies were done using ITER Case 98 plasma parameters ("semi-detached" plasma with 1\% Neon) [66]. This included, for example, variations in the non-thermal D-T molecule sputtering yield. The current ITER "reference case 133" ("shallow detached") plasma was also studied, but in less detail due to time limitations. To first order, the case 133 plasma leads to about $40 \%$ more tritium codeposition than case 98 , this being due to more net chemical erosion. Roughly speaking, the analysis gives a likely range of codeposition rates of 10-20 g-T/1000 s pulse. As explained previously, this analysis is subject to some uncertainties due to the lack of relevant data and code validation for the detached plasma zone.

In addition to the divertor analysis, the tritium codeposition in wall-sputtered redeposited beryllium has been computed (for Case 98 plasma). Using worst-case (coldest) surface temperatures for the critical beryllium deposition zones of $\sim 230 \mathrm{C}$, we estimate approximate worst-case codeposition rates as $\sim 0.1 \mathrm{~g}$-T/1000s using low-oxygen-content TPE trapping data [31] or 0.6 g-T/1000s using "carbon-corrected" Mayer et al. data [33]. In either case the wall-derived $\mathrm{T} / \mathrm{Be}$ codeposition is much less than codeposition from carbon sputtering in the divertor. The main reason for this is simply the low overall wall beryllium erosion, predicted for the semi-detached regime, with its low overall charge-exchange flux to the walls. 
While the amount of tritium retained is high, the predicted tritium retention fraction in ITER, based on fuel throughput, is lower than that observed in present-day tokamaks (TFTR, JET see for example $[23,27,28])$. However, the retention fractions in terms of throughput experienced in existing machines cannot be simply applied to ITER because codeposition is mainly related to the net-erosion rates as a function of spatial position on the wall and divertor surfaces together with the impurity transport in the SOL. In general, the fraction of tritium retained in a tokamak is a complex function of the machine and plasma geometry, material coverage and discharge history. TFTR, for example, operated at low wall temperatures which enhances the amount of deuterium stored in the codeposits and decreases the efficiency of clean-up removal techniques. In addition, low density plasma scenarios with high edge temperatures, as used routinely in TFTR, result in large carbon impurity release rates which in turn results in thicker carbon deposits. In JET, erosion/ redeposition and tritium uptake in the codeposited layers was found to be dependent on the divertor geometry: the pattern of deposition changed markedly when the Mk-II divertor replaced the Mk-I divertor. Also, results from present-day machines (with several second pulse length) may be affected disproportionately by transient effects such as impurity generation and transport during the start-up and shutdown periods. First-wall erosion/redeposition, for instance, can be markedly different during start-up and shutdown than during the flat-top period where an equilibrium divertor plasma is established. In contrast, the $1000 \mathrm{~s}$ ITER pulse length makes the startup/shutdown effects much less significant. In addition, the ITER edge density is some ten times higher than that in JET or TFTR, the walls are hotter than TFTR, and the amount of oxygen contamination could be lower. Retention models need to be benchmarked against the experience of existing machines to identify the contribution of various effects. Specific recommendations will be made in Sec. 7 on how to reduce these uncertainties in order to make confident predictions to ITER.

\section{Tritium inventory control and removal from the codeposited layers 6.1. Clean-up needs and likely methods in ITER}

It was shown in Sec. 5 that tritium will accumulate by codeposition within the ITER vacuum vessel in regions that are not undergoing active erosion by interaction with the plasma. The prospect of ITER reaching its in-vessel tritium inventory limit in the order of one hundred pulses highlights the critical need to develop and test in-situ efficient tritium recovery and cleaning techniques. 
The mechanisms of tritium removal from the codeposited layers are as important to the operation of ITER as the mechanisms of retention. If in-situ codeposition removal techniques are rapid and effective and plasma performance is recovered promptly after the cleaning, then the limitations associated with tritium retention become less important for the long-range inventory problem.

\subsection{Status and perspectives of techniques for tritium removal from codeposits}

The tritium recovery experience in TFTR and JET is summarised in Table 5. It is worth noting that tritium removal from existing tokamaks proved to be successful to achieve the required limits; however, it took place over several weeks as compared to the total time of about $1,000 \mathrm{~s}$ of high power DT discharges. The tritium removal rate in ITER will need to be orders of magnitude higher when considering its operational schedule.

\section{Insert here table 5}

In principle, there are two mechanisms by which hydrogen isotopes can be removed from materials: thermal desorption and ion-induced desorption. However, past studies have shown that thermal desorption of tritium from codeposited a-C:T layers requires in-vacuum temperatures above $700 \mathrm{C}$ [67] and $\mathrm{T}$ removal by ion bombardment is limited to depths corresponding to the ion range, typically a few nm for plasma discharges. Thus, removal of $\mathrm{T}$ from $\mu \mathrm{m}$ thick codeposits requires removal of the codeposits themselves. Tritium can be removed from thick codeposits by oxidising the a-C:T layers to produce volatile DTO, CO, and $\mathrm{CO}_{2}$, leading to the release of hydrogen. The presence of DTO in the torus exhaust raises a potential safety concern due to its high radio-toxicity and special processing needs. Alternative techniques have been proposed but need further development. These are based on laser surface heating and $\mathrm{CO}_{2}$ pellet ablation (see section 6.3 below).

In Ref. [1] possible methods of tritium removal are summarised with emphasis on those that do not require vessel opening and remote handling access. A significant constraint for tritium removal techniques for ITER is the presence of the toroidal field. The superconducting coils generating the field are rated for 1,000 on/off cycles in their lifetime, so cleaning techniques performed, e.g. weekly, will need to be done with the toroidal field on.

\subsubsection{Codeposit removal with high temperature oxidation: laboratory and tokamak studies}


Several laboratory measurements of $\mathrm{H} / \mathrm{D} / \mathrm{T}$ release and removal rates from codeposited films and D-implanted graphite during exposure to air or oxygen are now available $[68,69,70,71$, $72,73,74,75]$. In this review, we focus on two key findings: (i) the release of $\mathrm{D}$ in an oxygen-containing atmosphere occurs mainly in conjunction with $\mathrm{C}$ erosion; (ii) the $\mathrm{D}$ removal and C-erosion rates strongly depend on the film structure. Annealing of C:D films in air or oxygen causes surface oxidation in contrast to vacuum annealing which leads to thermal desorption of $\mathrm{D}_{2}$ and hydrocarbons at temperatures between $600-730 \mathrm{C}$. These temperatures are substantially higher than the range of temperatures used in oxidation experiments (typically $<380 \mathrm{C}$ ). The latter temperature range was intentionally kept low to simulate reactor surface temperatures that might be possible in the presence of air or oxygen in tokamaks. The D-release rate during oxidation is a critical function of the annealing temperature and the film structure. Hard films (H/C0.4) require temperatures of at least 380C [74] while soft films $(\mathrm{H} / \mathrm{C}>1)$ start to decompose already at $250 \mathrm{C}[75]$.

From an analysis of the reaction products formed by exposing an a-C:D film to ${ }^{18} \mathrm{O}_{2}$ at $470 \mathrm{~K}$, Haasz et al. [71] concluded that essentially all of the $\mathrm{D}$ is removed via $\mathrm{D}_{2} \mathrm{O}$ formation, and $\mathrm{C}$ is removed by the formation of $\mathrm{C}^{18} \mathrm{O}$ and $\mathrm{C}^{18} \mathrm{O}_{2}$. No $\mathrm{D}_{2}$ and no methane was observed. Surface analysis after ${ }^{18} \mathrm{O}_{2}$ exposure using XPS and SIMS revealed the appearance of carbonyl groups and an increase of hydroxyl groups due to surface oxidation [71]. The scheme for thermal oxidation of hydrocarbon polymers provides a plausible reaction mechanism leading to the emission of $\mathrm{D}_{2} \mathrm{O}, \mathrm{CO}_{2}$ and $\mathrm{CO}$. This mechanism is consistent with the observed surface complexes [71].

D removal from hydrogenated films was also studied under exposure to other atmospheric gases. Nitrogen exposure and heating in vacuum at or below $570 \mathrm{C}$ was found to have no effect on the release of deuterium from D-implanted layers [70]. On the other hand, exposure of D-implanted layers [70], as well as TFTR codeposits [72], to moist air did result in D removal, but with no evidence of $\mathrm{C}$ erosion. It is suggested that $\mathrm{D}$ is removed via isotope exchange between the impacting $\mathrm{H}_{2} \mathrm{O}$ and the trapped $\mathrm{D}$ in the film. Comparing the effectiveness of oxygen and water, oxygen was seen to be considerably more effective in removing the trapped $\mathrm{D}[70,72]$.

Based on the results discussed above, tritium can be removed from thick codeposits of carbon and tritium by heating the deposits in air or oxygen. However, it is evident that the D-removal 
and C-erosion rates depend on the film structure, and differ greatly for laboratory-produced films and codeposits produced in tokamaks. C-erosion rates from hard-a-C:D films and Dimplanted layers are very similar and are of the order of a few to 10 's of nm per hour at temperatures < 350C [68-75]. In contrast, measured $C$-erosion rates for tokamak codeposits (see for TFTR Ref. [69,72], JET [72], DIII-D [72], ASDEX-U [74, 75]) are 2-3 orders of magnitude higher under similar conditions. Available results from tokamak codeposits indicate that $\mathrm{C}$-erosion rates in oxygen or air range from $\sim 1-10 \mu \mathrm{m} / \mathrm{h}$ at $250-350 \mathrm{C}$ temperature [72-75].

In order to extrapolate the above results to ITER with confidence, further studies of $D(T)$ removal from tokamak codeposits from various machines (TFTR, ASDEX-U, TEXTOR, JET, DIII-D) are needed. These studies should include analysis of the film stoichiometry and microstructure and impurity concentrations. An investigation of the oxygen pressure dependence of the C-erosion and D-removal rates and the effect of humidity added to oxygen on these rates is also of interest.

Three critical issues need further consideration in the application of the oxidation technique for T-removal to ITER. First is the question of post-oxidation plasma performance recovery, where only limited tokamak experience is available $[76,77]$. The second issue is related to the effect of oxygen on hot surfaces [e.g., beryllium, tungsten, copper, joints, etc.] of other components in the vacuum vessel. The third is the implications for the pumping and tritium plant when large quantities of DTO are present in the torus exhaust. Definitely, more work is recommended on this front.

First experiments in a tokamak using oxygen with hot walls $(350 \mathrm{C})$ to remove codeposits have been started in TEXTOR; preliminary results are presented at this conference [77]. In the initial tests performed in TEXTOR the external pumps were closed and the vessel was filled with ${ }^{16} \mathrm{O}_{2}$ or with ${ }^{18} \mathrm{O}_{2}$ isotopes to pressures ranging between 0.005 up to about $\sim 0.2$ Torr. At a filling pressure of $<0.01$ Torr, most of the oxygen was absorbed on the wall and the remaining 10-20\% oxidized the deposits to form $\mathrm{CO}$ and $\mathrm{CO}_{2}$ which was then released. At higher filling pressures of $\sim 0.2$ Torr, the fraction of oxygen adsorbed decreased by $20-30 \%$, whereas the fraction of $\mathrm{CO}$ formation was about constant and the formation of $\mathrm{CO}_{2}$ increased. Encouragingly, TEXTOR did not experience any long term adverse consequences after the use of oxygen to remove deuterium, and high performance plasma operation could be recovered after several minuets of GDC in helium and deuterium. Further experiments are 
planned (see ref. [77]). However, there is a need to investigate whether and to what extent collateral damage resulting from use of oxygen affects the surrounding materials, bolts, joints welds, etc.

\subsubsection{Codeposit removal with GDC, ECR and ICR plasma discharges}

Glow discharge cleaning: In the absence of magnetic fields, He-O glow discharges can produce rapid, controlled codeposit removal with minimal O-contamination. Erosion rates of $0.4 \mu \mathrm{m} / \mathrm{h}$ have been observed for graphite erosion and about 3 times greater for TFTR codeposits [78]. Laboratory studies [78] have determined this erosion to be a 2-step process: oxidation, followed by particle-induced desorption, with the maximum erosion rate limited by the latter. Temperatures in excess of $250^{\circ} \mathrm{C}$ are required for rapid thermal desorption of $\mathrm{CO}$ from carbon surfaces [78]. Helium ions of a few hundred $\mathrm{eV}$ have a high $\mathrm{CO}$ desorption yield, typically several orders higher than for electrons or photons. Rapid, efficient evacuation of the desorbed impurities from the system is also important. Dissociation and redeposition are primarily caused by energetic electrons; thus, electron densities and energies should be kept as low as possible. This conclusion is supported by conditioning studies with Taylor discharges and ECR. In both cases desorbed impurities were efficiently evacuated only after the discharge was terminated.

The erosion rate for He-O GDC was found to decrease with time due to surface texturing. This texturing has been observed for several materials and appears to be a characteristic of bombardment at a single well-defined angle, in this case, normal incidence. Accordingly, it is argued that this texturing will be eliminated if impact is random, as produced by discharges generating neutral particles. As a result, it is concluded that energetic neutral atom bombardment from a low pressure, low temperature plasma should produce the maximal $\mathrm{CO}$ desorption with minimal redeposition or texturing

Ion cyclotron resonance (ICR) discharge cleaning (DC): In a strong magnetic field, modelling shows that large fluxes of energetic neutral He can be produced by direct He ICR. This is due to helium's relatively small cross-section for scattering compared to charge exchange. Wall fluxes of neutral $\mathrm{He}$, greater than the ion fluxes with $\mathrm{He}$ GDC, can be produced by an RF geometry which directly heats the He ions. In addition, at low pressures energy transfer from He to the electrons is slow and should result in minimal electron heating. For the recently reported ICRF experiments in TEXTOR [79], an RF geometry and frequency 
were used which energised $\mathrm{He}$ ions through the directly-energised electrons. This resulted in a small net $\mathrm{H}$ desorption rate from an $\mathrm{H}$-loaded surface. It appears likely that rapid ionisation of desorbed species by the hot electrons prevented their evacuation. Similar conclusions can be reached for the recent TORE-Supra studies [80]. Clearly, electrons should be heated only to the level necessary to sustain the plasma.

Laboratory experiments are in progress at SNL to assess the potential of ICR conditioning for ITER. These studies will evaluate the erosion rate for TFTR-like codeposits using He-O plasmas. They use a Penning ion trap in a $4 \mathrm{~T}$ superconducting solenoid and a sample geometry which prevents ions from reaching the codeposit surfaces. The experiment is designed to measure and optimise the erosion rate by He-O ICR and to compare this rate with that which can be achieved by He-O GDC. Initial results show very efficient formation of atomic $\mathrm{O}$ and significant $\mathrm{CO}$ production under bias conditions which prevent energetic ion impact with carbonised surfaces. It is believed that much of this $\mathrm{CO}$ signal resulted from atomic $\mathrm{O}$ migration into carbonised regions of the vacuum system. Efforts are underway to reduce this background and separate it from the $\mathrm{CO}$ desorbed by ICR-energised neutrals. If properly interpreted, the existence of this $\mathrm{CO}$ background indicates that atomic $\mathrm{O}$ readily migrates among oxidised metal surfaces until it locates a carbon atom. This mobility gives atomic $O$ the capability to remove codeposits from shadowed regions in ITER, perhaps rapidly at elevated temperatures. Ultimately, these laboratory studies will attempt to quantify this migration along with the erosion rate. They will also examine the texturing and $\mathrm{O}-$ contamination of materials exposed to the atomic $\mathrm{O}$ environment.

Electron cyclotron resonance (ECR) discharge cleaning (DC): The carbon removal rates observed in laboratory hydrogen ECR, for unbiased samples at about $80 \mathrm{C}$, are about $20 \mathrm{~nm} / \mathrm{h}$ $[81,82,83]$. The films used in this study were amorphous carbon produced in several ways. The carbon film thickness was monitored in-situ during removal either by monitoring the electrical resistance of the film or ellipsometry, and ex-situ by ion beam analysis. The erosion was found to depend critically on the actual film structure at the surface. While the microscopic processes active during interaction of carbonaceous surfaces with hydrogen discharges are relatively well understood, the situation is less satisfying for the interaction with other reactive gases, in particular with oxygen. Therefore, an experimental study was started at IPP-Garching to investigate the erosion of a-C:H films in low-pressure discharges using a variety of gases with particular emphasis on oxygen [83]. Among the investigated gas 
compositions, oxygen shows always the highest erosion rates; the relative rates behave as $\mathrm{O}_{2}$ : $\mathrm{D}_{2}: \mathrm{H}_{2} \approx 10: 2: 1$. The erosion rates increase with substrate temperature, ion energy, and ion flux. These correlations are true for soft and hard $\mathrm{C}: \mathrm{H}$ films, although the absolute rates differ significantly. Erosion rates of 1.7 and $3.6 \mu \mathrm{m} / \mathrm{h}$ were measured for hard a-C:H films and oxygen plasmas with surfaces maintained at floating potential at $25 \mathrm{C}$ and $350 \mathrm{C}$, respectively. The rates increase with increasing ion energy. The rates for soft $\mathrm{C}: \mathrm{H}$ films are roughly a factor of two higher [83]. For discharges in pure oxygen, no large oxygen inventories were found in ex-situ analyses (XPS and ion-beam analysis) of a-C:H samples. The dominant erosion products as measured by mass spectrometry are $\mathrm{H}_{2}, \mathrm{CO}, \mathrm{CO}_{2}$, and $\mathrm{H}_{2} \mathrm{O}$. Etching by neutral species (most probably atomic oxygen) was demonstrated to occur, but the underlying processes remain unclear [83].

Electron cyclotron discharge cleaning is being tested as a method for removal of a-C:D films in a tokamak [84]]. Removal rates in excess of $3 \mathrm{~nm} / \mathrm{h}$ were measured using a deuterium ECDC plasma in the Alcator C-Mod tokamak.

Application of this technique to mitigate tritium accumulation in ITER depends on several unresolved questions. They include: (a) how much $\mathrm{CH}$ is removed by ions and neutral species; (b) dependence of the removal rate on the absorbed RF power density, plasma temperature, plasma density, gas pressure, gas throughput, vessel geometry, magnetic field configuration, angle of field onto surface, etc; (c) if ECDC needs to be localised in a tokamak (e.g. in the divertor) by localising the RF power absorption close to the surface to be cleaned; (d) if $\mathrm{ECDC} / \mathrm{ICDC}$ in a tokamak can remove $\mathrm{CH}$ from the vessel, or just redistribute it from one region to another, i.e. how much $\mathrm{CH}$ is removed by $\mathrm{ECDC}$ and how much is redeposited elsewhere (via chemically reactive radicals) before being pumped out; (e) active conditioning requirements to remove residual $\mathrm{O}$; (f) detrimental effects of $\mathrm{O}$ plasma in tokamaks.

\subsubsection{Codeposit removal with other methods.}

A tritium removal technique using $\mathrm{CO}_{2}$ pellet cleaning is being investigated [85]. With $\mathrm{CO}_{2}$ pellet blast cleaning, widely used in the semiconductor and nuclear industries, pellets sublime on impact leaving no chemical or pellet residue. Cleaning can occur by particle abrasion, thermal shock, and, according to Hills [86], by chemical solvation in a transient liquid $\mathrm{CO}_{2}$ film that forms upon pellet impact. The procedure works best for soft films that are soluble in $\mathrm{CO}_{2}$ and lie on hard substrates. $\mathrm{CO}_{2}$ pellet cleaning has successfully been used on $\mathrm{Be}$ films 
from JET [87]. SNL routinely cleans the vacuum chambers in the Plasma Materials Test Facility using $-3 \mathrm{~mm}$ "hard" cylindrical $\mathrm{CO}_{2}$ pellets, which are used elsewhere to remove paint from tools. The effectiveness of this method in removing codeposited tritium layers from carbon tiles is not known. Preliminary tests using existing equipment at SNL did remove the surface layer from a graphite tile from the DIII-D tokamak but also severely eroded the tile. Better control of the removal rate by using softer pellets is being explored.

Finally, a method which is being proposed and that may have a sufficiently high recovery rate could be in-situ rapid heating of codeposited layers in vacuum or inert gas using an impinging laser beam or other form of surface heating [88]. Modelling shows that exposure to a multi$\mathrm{MW} / \mathrm{m}^{2}$ laser flux for approximately $10 \mathrm{~ms}$ raised the temperature of a $50 \mu \mathrm{m}$ codeposited layer to $750-1750 \mathrm{C}$, a temperature at which tritium would be released. This method avoids potential collateral effects associated with the use of oxygen. Experimental tests are needed to evaluate its applicability.

\section{Further R\&D needs}

In this section, we identify some of the most important unresolved in-vessel tritium issues and provide some recommendations on the $R \& D$ needed for their resolution.

\subsection{Reconciliation of tokamak retention data through development of appropriate models}

Detailed knowledge of the production and transport of the eroded material is extremely important in ITER, and in any future D-T fuelled tokamak. To date, there exist no global models of retention that have predicted the observed levels of retention in tokamaks. It is necessary and urgent to improve the quantitative understanding of retention and develop models that can be validated by comparing the predicted retention with that experienced in existing machines. These models would form the best basis for predicting the $\mathrm{T}$ retention in ITER. There is, in particular, a need to provide a physically realistic explanation of the amount of $\mathrm{D}(\mathrm{T})$ retained in codeposited layers of existing tokamaks, in particular in JET, their location, and the source of carbon which has produced these layers, and to extrapolate this to ITER. One of the most urgent needs is to learn more on the mechanisms and the controlling parameters leading to the distribution of tritium and film/ flakes in divertor configurations tested in present-day tokamaks.

\subsection{Methods for removal of tritium from the codeposited layers}


Development and testing of techniques to remove the C-based codeposited layers must continue at a fast pace to establish technical feasibility and better quantification of processes. Although it is clear from laboratory experiments that tritium can be removed from thick codeposits of carbon and tritium by heating the deposits in air or oxygen or using plasma discharges with $\mathrm{O}$, the efficient removal of tritium from the surface of in-vessel components of ITER remains somewhat speculative; there still remain several questions concerning the efficiency of removal and the proposed techniques need to be demonstrated in tokamaks. As long as we have not demonstrated tritium removal in a realistically large, complicated vacuum chamber with many potential trap sites, small laboratory experiments may not easily be scaled to the ITER situation for tritium removal.

\subsection{Plasma simulator experiments modelling and laboratory studies}

There are several areas of concern which require continuing investigations using small scale experimental laboratory systems. One of the most important includes mixed-material effects. Some results are becoming available from PISCES and other experiments which are beginning to map out the conditions necessary to form carbon-containing mixed-material layers on both beryllium and tungsten. However, the experimental database remains very meagre and there is a need to continue experiments and modelling for basic understanding.

Additionally, $\mathrm{D}(\mathrm{T})$ retention experiments should be conducted in $\mathrm{n}$-irradiated $\mathrm{Be}$ samples together with permeation engineering tests of duplex structures mimicking the actual armour material, the interface joint, and the copper-alloy heat-sink substrate. It is true that most of the tritium found in beryllium samples exposed to a tritium plasma is in the implant zone, however, it is still not accurately known how much tritium escapes this region to permeate deeper into the beryllium. There could still be permeation occurring with a low concentration but rapid migration. Experiments are also required to examine the effect of radiation damage on the tritium retention in beryllium. If there are radiation-induced traps located throughout the beryllium bulk, these traps are only important if the tritium is able to reach them. Finally, experiments supported by modelling are urgently needed to determine the mechanism, the magnitude of chemical sputtering, and its dependence on plasma parameters (energy and flux up to few times $10^{23}$ ions $/ \mathrm{m}^{2} \cdot \mathrm{s}$ ).

\subsection{Tokamak experiments to confirm approaches}


Bench-top experiments, although very useful to probe fundamental processes, cannot provide alone the level of understanding required to predict all the complex interactions in tokamaks. Therefore, dedicated tokamak experiments are urgently needed to provide relevant complementary data in the areas of tritium retention and removal, gross and net erosion, wall conditioning, dust production, accumulation and removal. The complex and varied discharge history in tokamaks makes "archaeological" comparisons of post-campaign in-vessel components with retention models of limited utility. Real time in-vessel edge diagnostics need to be routinely implemented to provide the needed experimental data that will challenge and advance models. Although some of such techniques exist [see refs: 89, [90, 91, 92, 93, 94], they are not in routine use. Real time measurements of erosion rates, by installing for example film thickness diagnostics, and a means of measuring retention under different operational conditions (startup/shutdown, disruptions, attached/detached divertor, high power operations) are needed.

Erosion of the main chamber wall by $\mathrm{C}-\mathrm{X}$ neutrals should not be forgotten. In contrast to the divertor, erosion rates at the wall may be low enough that the tiles don't disappear, but because the area is large, the total amount of eroded material may be significant and it must go somewhere, probably to the divertor, and this might affect the composition of materials in the divertor and therefore change the divertor performance.

Finally, the recycling of neutral atoms, radicals and molecules, including impurities, between surface and plasma edge needs closer scrutiny in tokamaks and laboratory experiments. Especially for high density low temperature detached plasma regime where neutrals play an important role and conventional plasma diagnostics like Langmuir probes and spectroscopy don't work very well.

Tests are required on tokamaks with the proper impurities and wall materials to provide a realistic test bed which would closely mirror the situation proposed for ITER (i.e., beryllium walls and carbon and tungsten in the divertor). Such experiments would help answer some of the relevant questions and address synergistic effects not easily determined in laboratory simulation experiments and one-material lined tokamaks. These include: (i) the nature, magnitude and location of tritium codeposition and dust to be expected in ITER; (ii) the development and testing of engineering solutions to mitigate codeposition and/or ease the removal of codeposited films; (iii) testing and implementation of tritium clean-up procedures, if required, and subsequent conditioning methods; (iv) the effect on hydrogen (tritium) 
retention in the wall; (v) mixed-materials effects; (vi) operational aspects of using beryllium on the first-wall. Such experiments would provide a realistic test bed for model development and validation and would lead to there being a much smaller step between present understanding of these key subjects and the expected experience on ITER.

\subsection{In-vessel tritium and dust diagnostics}

In-vessel diagnostic techniques need to be developed to ensure that codeposited tritium in the vessel of ITER remains below the maximum allowable limit. Additional R\&D activities and special equipment design are necessary to improve the accuracy of tritium measurements in the torus. There is a strong incentive to develop novel diagnostics in this area and to more fully use ones that exist (e.g., instrumented DiMES type probes). This include measurements at locations where erosion/redeposition, tritium and dust/debris is expected to accumulate. The finding emerging from existing tokamaks of localised areas of redeposition and accumulation of tritium in specific regions of the divertor, could represent favourable conditions for the development and implementation of dedicated diagnostics and removal methods. For each of the options identified, proof-of-principle and proof-of-performance experiments should be demonstrated in present-day tokamaks, and during the hydrogen operation phase of ITER. There is a need to plan an experimental campaign during ITER proton plasmas to determine the location and the extent of codeposited layers and dust and to demonstrate $95 \%$ recovery of trace $\mathrm{D}$ (or $\mathrm{T}$ ). The diagnostic requirements for this campaign must be defined. It should be noted though that the process of redeposition and dust production which occurs during the hydrogen phase of ITER is expected to be different from that during D-T operation, basically due to the differences in plasma parameters, power crossing the separatrix, possible isotopic dependence of chemical erosion, etc. Nonetheless, by understanding the processes during hydrogen operation, more confidence will be gained for extrapolating the amount of tritium inside ITER during D-T operation, based on localised measurements.

\subsection{Divertor design improvements}

Experience with the JET divertors indicates that small changes in design can result in a large accumulation of $\mathrm{D}(\mathrm{T})$ codeposited films and flakes. Conditions in the JET divertor have similarities to the ITER divertor, where non-line-of-sight deposition processes may lead to thick deposits saturated with $\mathrm{D}$ and $\mathrm{T}$ in similar cold regions. There is a need to conduct 
detailed modelling studies to establish a quantitative understanding of the deposition processes which are expected to take place under the anticipated operating conditions and to test these models by investigating the conditions controlling this deposition in JET. New design solutions should be explored to mitigate the consequences of codeposition. The present project strategy to resolve the problem relies on: 1) development of viable and efficient methods of removing in-situ tritium from the codeposited films; 2) optimisation of the design of the divertor subcomponents to mitigate codeposition. The latter can be achieved either by enhancing the formation of films in specific areas (e.g., by means of "cold catchers" which could be periodically heated to recover the tritium), or by keeping regions of probable redeposition hot during operation, with appropriate design measures, so that the films forming on these surface would trap only small amounts of tritium. In the next few years it is expected that the R\&D which is underway will help to determine the real potential of each of the proposed solutions, used alone or in combination.

It must be pointed out that if carbon were eliminated from the ITER divertor, the situation as far as tritium inventory is concerned could be radically different and the control of the tritium inventory would be much more manageable. However, dust from $\mathrm{Be}$ and $\mathrm{W}$ might still be an issue. The primary candidate in lieu of carbon for high heat flux regions is W. In anticipation of positive developments in this area, a development of a high-heat flux $\mathrm{W}$ vertical target is being considered as a possible alternative. However, it is important that the plasma physics community recognise that the projected levels of thermal loads expected during attachedplasma transients and disruptions lead directly to the use of carbon PFCs which in turn will potentially require the allocation of a significant fraction of ITER's operational schedule for detritiation. Efforts to reduce transients and mitigate disruptions must continue at the highest priority.

\section{Summary}

The design, operation and safety of ITER is affected by tritium retained in the redeposited films of eroded armour materials and implanted directly in the surfaces of components surrounding the plasma. These issues are being investigated both in laboratory experiments designed to probe the fundamental retention processes, and in tokamaks, as well as by modelling. 
Some of the most recent tokamak and laboratory data on hydrogen, deuterium and tritium retention in beryllium, tungsten and carbon materials which are candidate for cladding various surfaces of the ITER PFCs have been reviewed. The issue of mixed-materials effect which is still poorly understood and requires continuing investigations have also been addressed. These data have been gathered in the Home Teams as part of the R\&D program supporting the engineering design phase of ITER.

Codeposition of tritium with eroded carbon that originates from limited regions of the divertor plate near the separatrix strike points is expected to be the dominant T-retention mechanism in ITER. The in-vessel tritium inventory in the codeposited layers is predicted to accumulate at a rate in the range of $10-20 \mathrm{~g}-\mathrm{T} / 1000 \mathrm{~s}$ pulse. This rate strongly depends on the assumptions made for the plasma edge conditions, erosion yields, and other factors. Tritium accumulating in the codeposited layers in ITER has safety implications as it can be mobilised and released to the environment during a severe accident. Therefore, a safety limit on the accumulation of tritium will be imposed. This limit could be reached, under worst conditions, in a few days or weeks of operation. At this point, plasma operation could only be resumed after tritium recovery methods had removed the majority of tritium.

Efficient techniques of tritium removal from the codeposited layers will be essential in the operation of ITER. These techniques are beyond the experience of current tokamaks. Some of the principal methods that are being investigated and tested have been critically discussed in this paper, identifying the R\&D still required. Based on the encouraging results available from tests in laboratory experiments, and anticipating further positive developments in this area, it is conceivable that high temperature baking of the divertor system in an oxygen atmosphere in-conjunction with low-pressure plasma discharges with oxygen (e.g., ECR, ICR) could represent viables methods to efficiently control the build-up of tritium codeposition inventory in the ITER vessel. Further developments and optimisation of the divertor design, based on information provided by future dedicated operation experience in existing tokamaks, will also be very important to control the occurrence and mitigate the extent of the codeposition problem.

Recommendations for further urgent $R \& D$ which is needed to narrow the remaining uncertainties includes modelling work, experiments in both laboratory plasma simulators and tokamaks, as well as design improvements. In particular, there is a need to conduct experiments in existing tokamaks whose edge environment and PFC configuration closely 
mirror the material wall situation as proposed for ITER. Such experiments can offer opportunities for complex and non-linear plasma surface interactions beyond those presently accessible in laboratory investigations. Tests of this type have usually received low priority on present tokamaks, mainly due to the competition for machine time and resources with more conventional plasma physics experiments. There is, in particular, a need for dedicated operation time, diagnostics and instrumentation and in-vessel reconfigurations in tokamaks dedicated to addressing specific $T$ issues of high relevance for ITER, such as net erosion rates and redistribution of eroded material as well as mixed-materials effects. To be able to successfully compare the results to predictions, it will be necessary to improve the modelling and do good bench-marking tests, and improve communication/collaboration among plasma experimentalists, modellers and materials specialists.

\section{Acknowledgements}

The authors gratefully acknowledge the many helpful comments and conversation with Drs. $R$. Behrisch, P. Franzen, and M. Mayer of Max-Planck-Institute of Plasma Physics of Garching, Dr.W. Bohmeyer and Dr. D. Naujoks of Max-Planck-Institute of Plasma Physics of Berlin, Drs. E. Vietzke, P. Wienhold, A. Pospieszczyk of the Institute of Plasma Physics of the Forschungszentrum Juelich, Dr. J. Davis of the University of Toronto, Dr. C. Wu, Dr. D. Campbell, Dr. H. Pacher and Dr. G. Vieider of the Net Team, Dr. Ken Wilson and Dr. M. Ulrickson of Sandia National Laboratories, Prof. D. Ruzic of the University of Illinois at Urbana/Champaign, Dr. D. Whyte and F.C. Sze of the University of California San Diego, Dr. C. Wong of General Atomics, Dr. R. Aymar, Prof. Parker, Dr. Shimomura., Dr. R. Little, Dr. F. Perkins, Dr. A.R. Raffray, and R. Tivey of the ITER Joint Central Team.

This paper was prepared as an account of work performed under the Agreement among the European Atomic Energy Community, the Government of Japan, the Government of the Russian Federation, and the Government of the United States of America on Co-operation in the Engineering Design Activities for the International Thermonuclear Experimental Reactor ("ITER EDA Agreement") under the auspices of the International Atomic Energy Agency (IAEA). 


\section{Table captions}

Table 1 Total Chemical Erosion Yields (atoms C/ion) based on the 'mean values' resulting from the Garching and Toronto procedures.

Table 2: $\quad$ Tritium inventory in TFTR and JET.

Table 3: Design parameters and operating conditions of the PFCs in ITER (Basic Performance Phase). The first-wall and baffle will not be changed during the BPP, so a lifetime of about $8 \cdot 10^{6}$ seconds. The divertor is assumed to be changed out at the end of $\sim 3 \cdot 10^{6}$ seconds (about 2000-3000 full-power discharges).

Table 4: $\quad$ Summary of calculated tritium inventory ${ }^{\S}$ and permeation in ITER plasmafacing components for the Basic Performance Phase.

Table 5: $\quad$ Summary of tritium removal techniques used in TFTR and JET. 
Table 1 Total Chemical Erosion Yields (atoms C/ion) based on the 'mean values' resulting from the Garching and Toronto procedures.

\begin{tabular}{llllll}
\hline $\mathrm{D}^{+}$ & $\mathrm{E}(\mathrm{eV})$ & $500 \mathrm{~K}$ & $600 \mathrm{~K}$ & $700 \mathrm{~K}$ & $800 \mathrm{~K}$ \\
\hline 5 & 0.008 & 0.010 & 0.012 & 0.007 \\
& 5 & 0.012 & 0.016 & 0.018 & 0.014 \\
& 15 & 0.014 & 0.019 & 0.022 & 0.018 \\
\hline $\mathrm{T}^{+}$ & $\mathrm{E}(\mathrm{eV})$ & $500 \mathrm{~K}$ & $600 \mathrm{~K}$ & $700 \mathrm{~K}$ & $800 \mathrm{~K}$ \\
\hline & 5 & 0.009 & 0.014 & 0.014 & 0.009 \\
& 10 & 0.015 & 0.019 & 0.021 & 0.016 \\
& 15 & 0.017 & 0.022 & 0.025 & 0.020 \\
\hline
\end{tabular}


Table 2: Tritium inventory in TFTR and JET

\begin{tabular}{|c|c|c|c|c|c|c|}
\hline \multirow{3}{*}{ Description } & \multicolumn{3}{|l|}{ TFTR } & \multicolumn{3}{|l|}{ JET } \\
\hline & Run Period & & & Run PeI & lod & \\
\hline & '93-95 & 96 & '97 & 11/91 & $6 / 97$ & 9-11/97 \\
\hline Total number of discharges & 14724 & 5324 & 3619 & 2 & 293 & $\sim 300$ \\
\hline Discharges with NBI & 6134 & 2167 & 1609 & 2 & $>50 \%$ & $>50 \%$ \\
\hline Discharges with tritium NBI & 500 & 124 & 107 & 2 & 34 & $\sim 100$ \\
\hline Tritium processed $(\mathrm{g})$ & 73 & 17 & 15 & 0.1 & 23 & 77 \\
\hline Tritium Injected $(\mathrm{g})$ & 3.3 & 0.84 & 1.1 & 0.005 & 11.5 & 23.5 \\
\hline Tritium $T$ retained in-vessel $(\mathrm{g})$ & 1.7 & 1.6 & 1.8 & 0.004 & 4.4 & 11.5 \\
\hline Increment of $\mathrm{T}$ inventory $(\mathrm{g})$ & 1.7 & 0.81 & 0.76 & 0.004 & 4.4 & 8.6 \\
\hline Tritium removed at end of run $(\mathrm{g})$ & 0.96 & 0.49 & 0.84 & 0.0045 & 1.5 & 5.5 \\
\hline
\end{tabular}


Table 3: Design parameters and operating conditions of the PFCs in ITER (Basic Performance Phase)

\begin{tabular}{|c|c|c|c|c|c|c|c|c|}
\hline Component & $\begin{array}{c}\text { Surface } \\
\text { area }^{\dagger} \\
\left(\mathrm{m}^{2}\right)\end{array}$ & $\begin{array}{c}\text { Surface } \\
\text { mat'l/ } \\
\text { thickness } \\
(\mathrm{mm}) \\
\end{array}$ & $\begin{array}{l}\text { Heat flux } \\
\left(\mathrm{MW} / \mathrm{m}^{2}\right)\end{array}$ & $\begin{array}{c}\text { Oper. arm. } \\
\text { temp. } \\
\text { (front/ back) } \\
\text { (C) } \\
\end{array}$ & $\begin{array}{c}\text { Ion/ atom } \\
\text { flux } \\
\left(\mathrm{D}+\mathrm{T} / \mathrm{m}^{2} \cdot \mathrm{s}\right)\end{array}$ & $\begin{array}{c}\text { Energy } \\
(\mathrm{eV})\end{array}$ & $\begin{array}{c}\text { Fast neutron } \\
\text { flux }(\mathbf{k}) \\
\left(\mathrm{n} / \mathrm{m}^{2} \cdot \mathrm{s}\right)\end{array}$ & $\begin{array}{c}\text { Lifetime } \\
\text { (pulses }(1) / \mathrm{dpa})\end{array}$ \\
\hline \multicolumn{9}{|l|}{ First-wall } \\
\hline - Primary first-wall & $1025^{(a)}$ & $\mathrm{Be} / 10 \mathrm{~mm}$ & $0.25^{(\mathrm{d})}-0.5^{(\mathrm{e})}$ & $285 / 245^{(\mathrm{d})}$ & $10^{19} \div 10^{20}$ & $100-500$ & $(1.9 \div 2.3) \times 10^{18}$ & $10^{4} / 0.8-1(\mathrm{Be})$ \\
\hline - Start-up limiter & $8.5^{(b)}$ & $\mathrm{Be} / 4-5 \mathrm{~mm}$ & $\sim 8(f)$ & $\begin{array}{l}790 / 360^{(i)} \\
190 / 170^{(j)} \\
\end{array}$ & $10^{21} \div 10^{22(\mathrm{i})}$ & $100-500$ & $2.3 \times 10^{18}$ & $<10^{4} / 1(\mathrm{Be})$ \\
\hline - Upper baffle & 80 & $\mathrm{Be} / 10 \mathrm{~mm}$ & $1^{(d)}-2^{(e)}$ & $483 / 295(\mathrm{e})$ & $10^{19} \div 10^{20}$ & $100-500$ & $2 \times 10^{18}$ & $10^{4} / 1(\mathrm{Be})$ \\
\hline - Lower baffle & 109 & $\mathrm{~W} / 10 \mathrm{~mm}$ & $1.5^{(\mathrm{d})}-3^{(\mathrm{e})}$ & $640 / 360(\mathrm{e})$ & $10^{20 \div 10^{21}}$ & 100 & $1.1 \times 10^{18}$ & $10^{4} / 0.3-0.5(\mathrm{~W})$ \\
\hline \multicolumn{9}{|l|}{ Divertor } \\
\hline - Lower target & 74 & $\mathrm{CFC} /<20 \mathrm{~mm}$ & $<10^{(\mathrm{g})}-20^{(\mathrm{h})}$ & $1280 / 340(\mathrm{~g})$ & $<10^{24}$ & $<5$ & $4 \div 6 \times 10^{17}$ & $3 \times 10^{3} / 0.2-0.3(\mathrm{C})$ \\
\hline - Sidewall & 79 & $\mathrm{~W} / 15 \mathrm{~mm}$ & $2^{(\mathrm{d})}-5^{(\mathrm{e})}$ & $460 / 240^{(d)}$ & $10^{21} \div 10^{22}$ & $5-100$ & $(0.6 \div 1.1) \times 10^{18}$ & $3 \times 10^{3} / 0.3-0.5(W)$ \\
\hline - Dome & 84 & $\mathrm{~W} / 10 \mathrm{~mm}$ & $1^{(\mathrm{d})}-5^{(\mathrm{e})}$ & $315 / 210^{(\mathrm{d})}$ & $10^{21} \div 10^{22}$ & $5-100$ & $(0.6 \div 1.1) \times 10^{18}$ & $3 \times 10^{3} / 0.3-0.5(\mathrm{~W})$ \\
\hline - Cassette liner & $90 / 400^{(c)}$ & $\mathrm{W} /$ (louver) & $0.1-0.7$ & $1000-250^{(\mathrm{m})}$ & $<10^{23(\mathrm{n})}$ & $<1$ & $(3.5 \div 4.) \times 10^{17}$ & $\begin{array}{c}3 \times 10^{3} / 0.1-0.2 \\
(\mathrm{~W}) \\
\end{array}$ \\
\hline
\end{tabular}

$\dagger$ The total area of the plasma facing surface is about $1550 \mathrm{~m}^{2}$. No asymmetry of the plasma conditions of the inner and outer divertor leg is considered.

(a) including port limiter.

(b) start-up limiter modules occupy two mid-plane port.

ii (c) surface area of the louvers (see text).

(d) design average heat flux (at $1.5 \mathrm{GW}$ )

(e) design peak value at any condition.

(f) during start-up. During flat-top burn the limiter will experience the same load as the primary first-wall.

(g) peak load expected during normal semi-detached conditions.

(h) peak load expected during off-normal transients (10\% frequency, $10 \mathrm{~s}$ duration).

(i) during limiter operation.

(j) during divertor operation

(k) $\mathrm{E}>0.1 \mathrm{MeV}$

(l) $1000 \mathrm{~s}$ duration. (m) For a given input power density, the temperature varies then from the corner of the chevron to the copper part of the stem. For the case with 0.1

$\mathrm{MW} / \mathrm{m}^{2}$ the maximum temperature for $\mathrm{W}$ is $250 \mathrm{C}$ while the stem remains at about $175 \mathrm{C}$.

At $0.7 \mathrm{MW} / \mathrm{m}^{2}$ the maximum $\mathrm{W}$ temperature is $1000 \mathrm{C}$ while the stem remains at about $270 \mathrm{C}$.

(n) Dominant molecular hydrogen species at very low energy: $\Gamma_{H_{2}} \gg \Gamma_{H}$

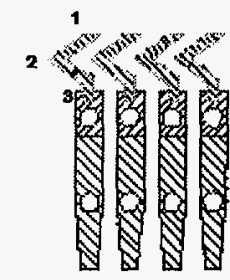


Table 4. Summary of TMAP4 calculated tritium inventory and permeation in ITER plasma-facing components for the Basic Performance Phase.

\begin{tabular}{|l|c|c||}
\hline Component & $\begin{array}{c}\text { Tritium Inventory } \\
(\mathbf{g})\end{array}$ & $\begin{array}{c}\text { Tritium Permeation Rate } \\
(\mathbf{g} / \mathbf{d})^{\dagger}\end{array}$ \\
\hline First-wall (implantation + breeding) & $106^{*}$ & $7.0 \times 10^{-4}$ \\
First-wall (inc, n-effect) & $194^{* *}$ & $3.4 \times 10^{-11}$ \\
Startup limiter & $9.2 \times 10^{-3}$ & $4.7 \times 10^{-7}$ \\
Upper baffle & 0.78 & $4.4 \times 10^{-5}$ \\
Lower baffle & 0.12 & $6.5 \times 10^{-7}$ \\
Upper vertical target & 31 & $8.1 \times 10^{-9}$ \\
Dome & 2.0 & $1.5 \times 10^{-6}$ \\
\hline
\end{tabular}

$\dagger \quad$ It assumed that $\sim 10000$ pulses are distributed uniformely over 10 years.

* Breeding assumed 14-MeV neutron current of $1.15 \mathrm{MW} / \mathrm{m}^{2}$, a peak value, as compared with $0.94 \mathrm{MW} / \mathrm{m}^{2}$ poloidal average, and production rates calculated by Forty et al. [53] from FISPACT for the first wall; trapping characteristics were those of unirradiated beryllium ( 0.0005 atom fraction, $0.8 \mathrm{eV}$ trap energy).

** In addition to breeding, this calculation included neutron-induced traps taken to be $2 \%$ atom fraction and $1.4 \mathrm{eV}$ trap energy, the values giving excellent replication of thermal desorption data of tritium from fully dense beryllium irradiated to ITER-like conditions in ATR reported by Baldwin and Billone [54]. Inventory was in first $10 \mu \mathrm{m}$ of beryllium.

*** Implantation-driven inventory in the carbon portion of the vertical target was estimated using Code DIFFUSE and found to be at the end-of-life and at the operating temperatures calculated from the surface heat load distribution, $1 \mathrm{~m}^{2}$. 
Table 5. Summary of tritium removal techniques used in TFTR and JET

\begin{tabular}{|c|c|c|}
\hline \multirow{2}{*}{$\begin{array}{l}\text { Machine } \\
\text { operation: }\end{array}$} & \multicolumn{2}{|l|}{ Comments } \\
\hline & TFTR & JET \\
\hline D tokamak pulses & Ineffective & $\begin{array}{l}\text { Tokamak pulses in deuterium (few thousands) only reduced the } \\
\text { in-vessel inventory by a factor of } 2 \text {; at the end of the campaign, } \\
\text { T removal by pulsing was only about } 10 \mathrm{mg} / \mathrm{day}\end{array}$ \\
\hline $\mathrm{He}-\mathrm{GDC}$ & Ineffective & Ineffective \\
\hline D-GDC & $\begin{array}{l}\text { Initial removal rate high }(>18 \mathrm{mg} / \mathrm{h}) \text {, declining to } 1 \mathrm{mg} / \mathrm{h} \text {. } \\
\text { Accesses only tritium on surfaces exposed to discharge. } \\
\text { Average removal rate: } 0.001 \text { to } 0.03 \mathrm{~g} / \mathrm{h} \text {. }\end{array}$ & $\begin{array}{l}\text { Ineffective. Only few hours of D-GDC were attempted due to } \\
\text { the high gas load on the Active Gas handling System (AGHS). } \\
\text {. The amount of tritium released was negligible. }\end{array}$ \\
\hline $\mathrm{D}_{2}$ gas soak & Ineffective & Ineffective \\
\hline Outgas & Ineffective & Ineffective \\
\hline ICRF & not applied & $\begin{array}{l}\text { One of the most effective clean-up method used in June prior to } \\
\text { repairs of the beam box used ohmic and ICRF pulses with } \\
\text { various strike points. The wall inventory was reduced from } 4.4 \\
\text { to } \sim 2.9 \mathrm{~g} \text { in a four-day period with } \sim 120 \text { pulses. }\end{array}$ \\
\hline $\begin{array}{l}\text { ECRH plasma } \\
\text { discharges }\end{array}$ & not applied & $\begin{array}{l}\text { It was used at JET (gas load on AGHS is much smaller) but } \\
\text { again T release was negligible. }\end{array}$ \\
\hline $\mathrm{HeO}-\mathrm{GDC}$ & Rate $5 \mathrm{mg} / \mathrm{h}$ - constant with time & not applied \\
\hline 718 torr room air & $\begin{array}{l}220 \text { mg removed, access to all surfaces. the removal is very } \\
\text { quick, }<1 \mathrm{~h} \text {, but it took about } 24 \mathrm{~h} \text { to process the air. }\end{array}$ & Removal is observed but quantities are being analysed. \\
\hline $\mathrm{N}_{2}$ vents & not applied & Ineffective \\
\hline Disruptions & $\begin{array}{l}\text { Flash heating of limiter surface near midplane. Release of } \\
\text { recently retained tritium. One time recovered } 0.014 \mathrm{~g} \text {, after a } \\
\text { major disruption, other times little removal seen.) }\end{array}$ & not quantified \\
\hline PDC & $\begin{array}{l}\text { Heats limiter to } 250^{\circ} \text { C. } 100 \mathrm{mg} \text { removed over } 23 \text { hours. } \\
\text { Average removal rate: } 0.004\end{array}$ & not applied \\
\hline Boronization & $\begin{array}{l}\text { Little tritium released, most near surface tritium already } \\
\text { removed. }\end{array}$ & not applied \\
\hline $\begin{array}{l}\text { Heating of divertor } \\
\text { support structure }\end{array}$ & not applied & $\begin{array}{l}\text { Prior to venting the divertor support structure, which sits at } 40 \mathrm{C} \\
\text { for most of the campaign, was heated to } 135 \mathrm{C} \text {. Only a very } \\
\text { small amount of gas desorbed, but at a high T fraction }(\sim 2 \%) \\
\text { giving only } \sim 6 \mathrm{mg} \text { of tritium. }\end{array}$ \\
\hline $\begin{array}{l}\text { Remote tile exchange } \\
\text { (RTE) }\end{array}$ & not applied & $\begin{array}{l}\text { Divertor tiles carriers and flakes have been physically removed } \\
\text { in the remote tile exchange (RTE. Quantities are being analysed. }\end{array}$ \\
\hline
\end{tabular}


[1] G. Federici et al. "Tritium inventory in the ITER PFC's: predictions, uncertainties, R\&D status and priority needs", to appear in Fus. Eng. \& Des.

[2] J.N. Brooks et al., "Erosion/redeposition analysis: status of modeling and code validation for semi-detached tokamak edge plasmas", these proceedings.

[3] C.H. Skinner, et al., "Modelling of tritium retention in TFTR", these proceedings

[4] C H Skinner, C Gentile, J Hosea, D Mueller, G Federici, R Haange, "Report on the IEA workshop on "Tritium Experience in Large Tokamaks: Application to ITER" submitted to Nuclear Fusion.

[5] Technical basis for the ITER detail design report, cost review and safety analyses, ITER EDA Documentation Series No. 13, IAEA, Vienna 1997.

[6] S J Piet, A Costley, G Federici, F Hekendorn, and R Little, "ITER Tokamak DustLimits, Production, Removal, Surveying", Proceedings of the 17th IEEE/NPSS Symposium on Fusion Engineering, San Diego, October 6-10, 1997).

[7] E. Vietzke and A. A. Haasz, "Chemical Erosion", in Physical Processes of the Interaction of Fusion Plasmas with Solids, eds. W. O. Hofer and J. Roth, Academic Press, Amsterdam, 1996, p. 135.

[8] J. W. Davis and A. A. Haasz, J. Nucl. Mat. 241-243 (1997) 37.

[9] A.A. Haasz et al., Supplement to Nucl. Fus. (in press).

[10] A. Horn et al., Chemical Physics Lett. 231 (1994) 193.

[11] M. Wittmann and J. Küppers, J. Nucl. Mat. 227 (1996) 186.

[12] J. Roth and C. Garcia-Rosales, Nucl. Fus. 36 (1996) 1647.

[13] B. V. Mech, A. A. Haasz and J. W. Davis, "A model for graphite erosion due to lowenergy $\mathrm{H}^{+}$and $\mathrm{D}^{+,}$, J. Appl. Phys., accepted.

[14] C. Garcia-Rosales, J. Roth, J.Nucl.Mater. 196-198 (1992) 573.

[15] B. V. Mech, A. A. Haasz and J. W. Davis, J. Nucl. Mat. 255 (1998) 153.

[16] A.Kallenbach et al., "Evidence for hydrogen flux dependence of the apparent chemical erosion yield of graphite under high flux conditions", Nucl. Fus., accepted for publication.

[17] H.Grote et al., these proceedings.

[18] V. Philipps, E. Vietzke and M. Erdweg, J. Nucl. Mater. 162-164 (1989) 550.

[19] D.M. Goebel, J. Bohdansky, et al., Fusion Tehnol. 15 (1989) 102.

[20] J.Roth, H.Plank,R.Schwörer, Physica Scripta T64 (1996) 67. 
[21] J.W. Davis and A.A. Haasz, J. Nucl. Mat. 255 (1998) 214.

[22] W. Jacob, "Surface reaction during growth and erosion of hydrocarbon films: A review", Thin Solid Films, in press.

[23] D, Mueller et al., Proceedings of the 17th IEEE/NPSS Symposium on Fusion Engineering, San Diego, Oct. 6-10, 1997.

[24] W. R. Wampler et al., J. Vac. Sci. Technol. A6 (1988) 2111-2115.

[25] M. Ulrickson, H.F. Dylla, P.H. LaMarche and D. Buchenauer, J. Vac. Sci. Technol. A 6, No.3 (1988) 2001-2003.

[26] H. F. Dylla and K. L. Wilson editors, "Tritium retention in TFTR", Princeton Plasma Physics Laboratory Report, PPPL-2523 and Sandia National Laboratory Report, SAND 88-8212, (April 1988).

[27] M. Keilhacker, “D-T experiments in JET", these proceedings.

[28] P. Andrew, "Tritium recycling and retention at JET", these proceedings.

[29] P. Andrew et al., Nucl. Fus. 33 (1993) 1389.

[30] A T Peacock et al., "Dust and flakes in the JET Mk-IIa divertor, analysis and results" these proceedings.

[31] R. A. Causey and D. Walsh, “Measurements of the codeposition of sputtered beryllium with deuterium" J. Nucl. Mater, in press.

[32] M. Mayer et al., J. Nucl. Mat. 230 (1996) 67-73

[33] M. Mayer, J. Nucl. Mat. 240 (1997) 164-167

[34] R.A. Anderl et al., "Hydrogen isotope retention in beryllium for tokamak plasma facing applications", to be submitted for publication in J. Nucl. Mat.

[35] R. P. Doerner et al., "Mixed-material coatings formation on PFC's", these proceedings.

[36] J. Roth, W. R. Wampler and W. Jacob, J. Nucl. Mat. 250 (1997) 23.

[37] F. C. Sze, R. P. Doerner and S. C. Luckhardt, these proceedings.

[38] R. A. Causey, K. L. Wilson, W. R. Wampler and T. Venhaus, "Tritium retention in tungsten exposed to intense fluxes of $100 \mathrm{eV}$ Tritions", these proceedings.

[39] A.A. Haasz, J.W. Davis, M. Poon, and R.G. Macaulay-Newcombe, J. Nucl. Mat., to appear.

[40] P. Franzen, C. Garcia-Rosales, H. Plank, et al., J. Nucl. Mat., 241-243 (1997) 1082.

[41] F. C. Sze et al., "Growth of redeposited carbon and its impact on isotope retention properties on tungsten in a high-flux deuterium plasma", these proceedings. 
[42] M. I. Baskes, Diffuse-83, SAND83-8231, Sandia National Laboratories, Livermore, CA (1983).

[43] W. Moeller, “PIDAT - Computer Program for Implant Diffusion and Trapping”, IPP 9/44, Max Planck Institut für Plasmaphysik, Garching, Germany (November 1983).

[44] G. R. Longhurst et al., "TMAP4 User's Manual”, EGG-FSP-10315, Idaho National Engineering and Environmental Laboratory, (June 12, 1992).

[45] W. R. Wampler, J. Nucl. Mat., 196 - 198 (1992) 981.

[46] A. A. Haasz and J. W. Davis, J. Nucl. Mat., 241-243 (1997) 1076.

[47] R. A. Causey et al., J. Nucl. Mat., $241-243$ (1997) 1041.

[48] G. R. Longhurst, "Saturation Effects in Plasma-Facing Mat”, J. Nucl. Mat. in press.

[49] V. N. Chernikov et al.,.J. Nucl. Mat. 233-237 (1996) 860.

[50] R. A. Anderl et al., J. Nucl. Mat.,196- 198 (1992) 986.

[51] R. A. Forrest, M. G. Sowerby, B. H. Patrick, D. A. J. Endacott, "The Data Library UKACT1 and the Inventory Code FISPACT", Nuclear Data for Science and Technology, Mito, Japan (1988) 1061.

[52] R. A. Forrest and D. A. J. Endacott, "FISPACT User Manual ", Harwell Report AEREM-3654(Rev), Harwell Laboratory, Oxfordshire, U.K. (1990).

[53] C. B. A. Forty, R. A. Forrest, J. J. Compton, C. Rayner, "Handbook of Fusion Activation Data Part 1: Elements Hydrogen to Zirconium", AEA UFS 180 (May 1993), Part 2 : Elements Niobium to Bismuth", AEA UFS 232 (May 1993), AEA Technology Fusion, Euratom/UKAEA Fusion Association.

[54] D.L. Baldwin and M.C. Billone, J. Nucl. Mater. 212-215 (1994) 948.

[55] W. L. Hsu et al., J. Nucl. Mat., 176-177 (1990) 218.

[56] G. Saibene et al., J. Nucl. Mat., 176-177 (1990) 618.

[57]R. A. Anderl et al., Fus. Tech. 21 (1992) 745.

[58]G. R. Longhurst, unpublished data.

[59] W. R. Wampler, Sandia National Laboratories, Albuquerque, NM, unpublished data.

[60] J.N. Brooks, in Atomic and Plasma-Material Interaction Processes in Controlled Thermonuclear Fusion, R. K. Janev and H. W. Darwin editors (1993) Elsevier Science Publishers B.V., p. 403.

[61] J. N. Brooks, Phys. Fluids 8 (1990) 1858.

[62] J. N. Brooks, Nuc. Tech./Fusion 4 (1983) 33 
[63] A. Kukushkin et al., these proceedings.

[64] D.N. Ruzic, Phys. Fluids B 5 (1993) 3140.

[65] J.N. Brooks and D.G. Whyte, "Modeling and Analysis of DIII-D/DiMES Sputtered Impurity Transport Experiments" MS in preparation.

[66] A.S. Kukushkin, H.D. Pacher, D. Coster, et al., "Effect of light impurities on the divertor performance in ITER", Controlled Fusion and Plasma Physics (Proc. 24th Eur. Conf. Berchtesgaden, Germany, 1997), ECA, vol. 21A, part III (1997) 100

[67] A.A. Haasz, P. Franzen, J.W. Davis, et al. J. Appl. Phys. 77 (1995) 66

[68] R.A. Causey, W.L. Chrisman, W.L. Hsu, et al. J. Vac. Sci. Technol. A 7 (1989) 1078.

[69] R.A. Causey, W.R. Wampler, and D. Walsh, J. Nucl. Mat. 176-177 (1990) 987.

[70] S. Chiu and A.A. Haasz, J. Vac. Sci. Technol. A 9 (1991) 747.

[71] A.A. Haasz, S. Chiu, J.E. Pierre et al., J. Vac. Sci. Technol. A (1996) 184.

[72] J.W. Davis, A.A. Haasz. “ Oxygen removal of codeposited a-C:D layers from tokamak tiles", these proceedings.

[73] A.A. Haasz and J.W. Davis, "The Removal of Codeposited Layers from TFTR Tiles By $\mathrm{O}_{2}$ Gas Exposure", J. Nucl. Mat. (in press).

[74] W. Wang, W. Jacob, J. Roth, J.Nucl. Mat. 245 (1997) 66.

[75] K. Maruyama, W. Jacob and J. Roth, "Erosion behavior of soft, amorphous deuterated carbon films by heat treatment in air and under vacuum", J. Nucl. Mater., submitted March 1998.

[76] Plasma performance recovery in JET after accidental air leak.

[77] V. Philipps et al., "Investigation of carbon layer removal and hydrogen release by oxygen ventilation of TEXTOR", these proceedings.

[78] D. Cowgill, unpublished data.

[79] H.G. Esser et al., J. Nucl. Mat. 241-243 (1997) 861.

[80] E. Gauthier et al., J. Nucl. Mat. 241-243 (1997) 553.

[81] C. A. Outen, J. C. Barbour and W. R. Wampler, J Vac. Sci. Technol. A9 (1991) 717.

[82] W. R. Wampler, J. Vac. Sci. Technol. A3 1067 (1985).

[83] W. Jacob, B. Landkammer, and C.H. Wu, "Removal of codeposited layers by ECR discharge cleaning", these proceedings. 
[84] R.T. Nachtrieb, B. L. LaBombard, J. L. Terry, J. R. Reardon, W. L. Rowan, W. R. Wampler, these proceedings.

[85] R. Nygren, perosnal communication.

[86] M.M. Hills, J. Vac. Sci. Technol. A 13 (1995) 30-34.

[87] S.M. Scott, A. Haigh, J. Schreibmaier, N. Davies, A. Porter, G. Saibene, Cleaning of the JET vacuum vessel using the carbon dioxide pellet blasting technique, JET Joint Undertaking Report \# JET-R(95)03, Abingdon, UK (1995).

[88] C. H. Skinner, H. Kugel, D. Mueller, B. L. Doyle, and W. R. Wampler, Proceedings of the 17th IEEE/NPSS Symposium on Fusion Engineering, San Diego, October 6-10, 1997.

[89] D. Whyte et al., "Divertor erosion in DIII-D, these proceedings.

[90] D Manos, T Bennett, M Herzer and J Schwarzman, J. Nucl. Mater. 196-198 933 (1992).

[91] P Wienhold, F Waelbroeck, H Bergsaker, et al., J. Nucl. Mater. 162-164, 369 (1989).

[92] H Y Guo and B Terreault, Rev. Sci. Instrum. 64 (1993) 700.

[93] D Bourgoin, G G Ross, S Savoie, et al., J. Nucl. Mater. 241-243, 765 (1997).

[94] W R Wampler and S J Kilpatrick, J Vac Sci. Technol. A7, 1083 (1989). 
Figure captions

Figure 1 Cross section of ITER showing the major plasma facing components.

Figure 2 (a) In-vessel configuration of the divertor region (Mk-II) for the first JET Divertor Tritium Experiment (DTE1); (b) Detail of the water-cooled louvres behind the slot at the inner-corner of the divertor where heavy deposits and flakes have been observed.

Figure 3 The TMAP4 code estimates substantially higher tritium inventory growth in the ITER Be first-wall $(1.02 \mathrm{~kg})$ during the BPP using the recombinationlimited assumptions than it does when saturation effects are considered $(5.0 \mathrm{~g})$. 


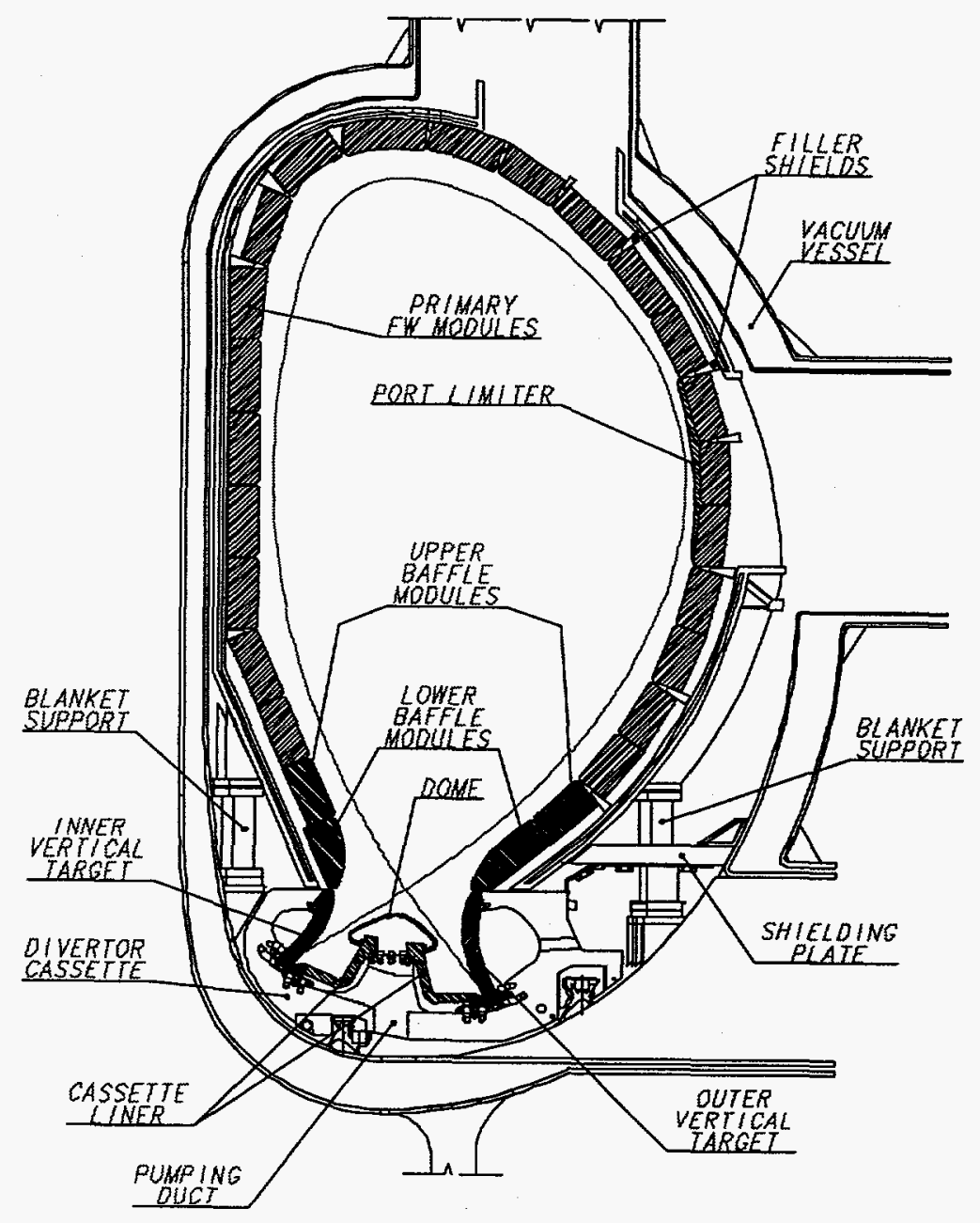

Figure 1 


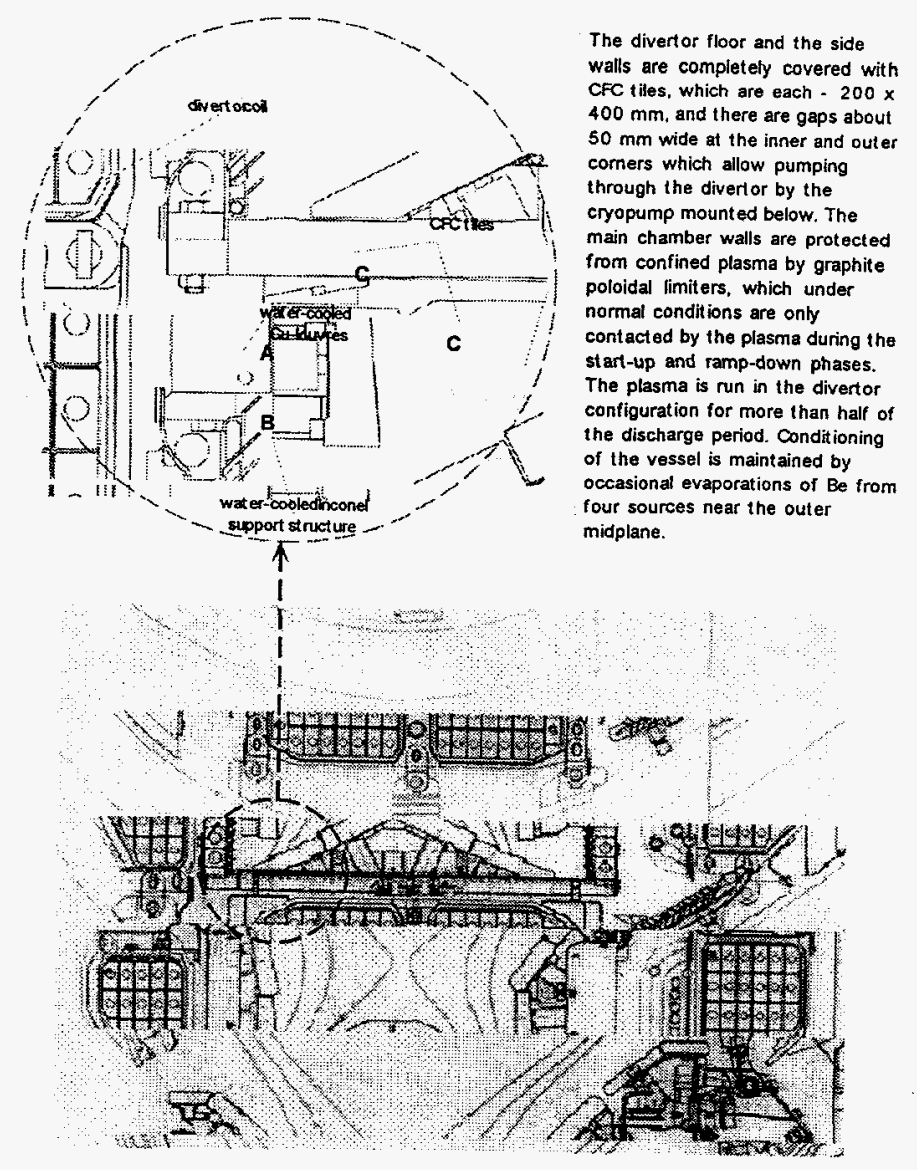

Figure 2 


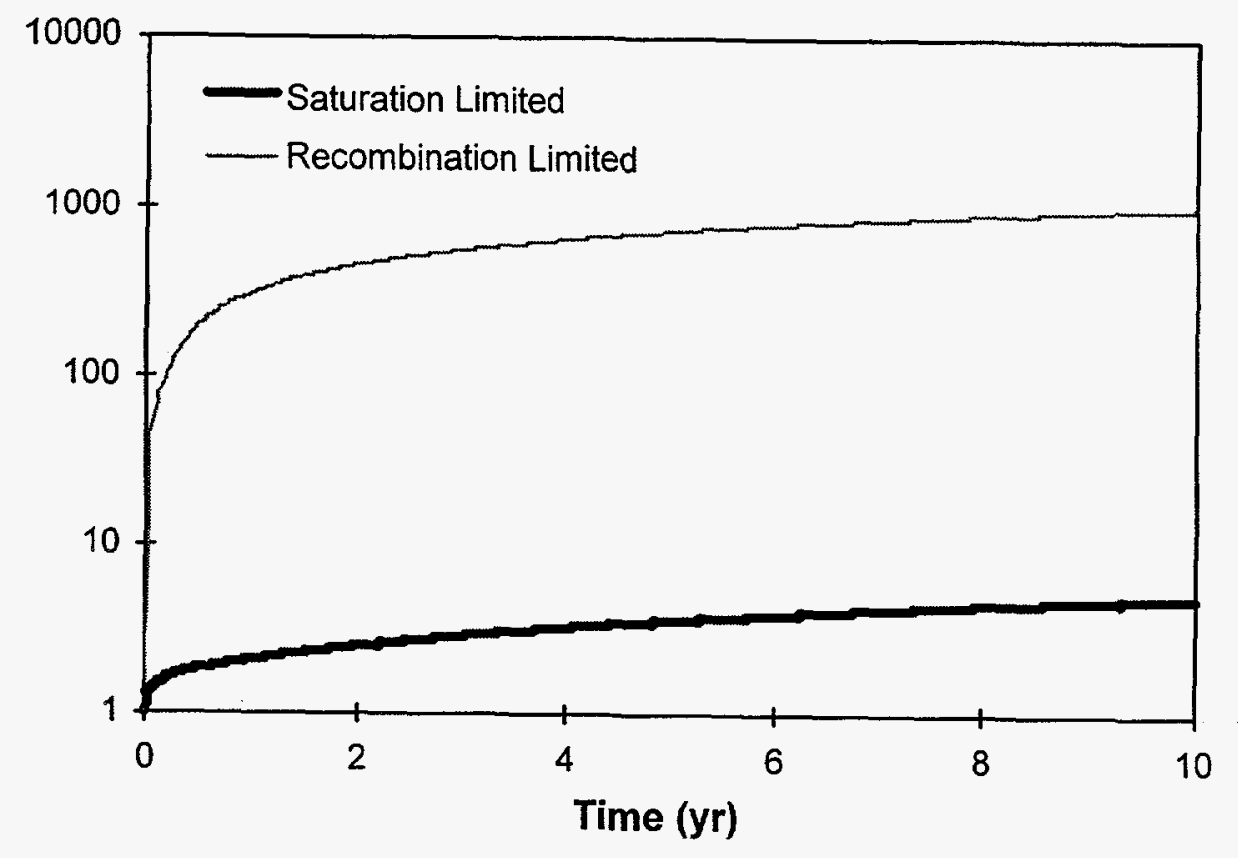

Figure 3. 